\title{
Light Potentials of Photosynthetic Energy Storage in the Field: What limits the ability to use or dissipate rapidly increased light energy?
}

\section{Atsuko Kanazawa, ${ }^{1,2}$ Abhijnan Chattopadhyay ${ }^{1,3}$, Sebastian Kuhlgert ${ }^{1}$, Hainite \\ Tuitupou', Tapabrata Maiti ${ }^{3}$ and David M. Kramer ${ }^{1,4 *}$}

1 MSU-DOE Plant Research Lab, Michigan State University, East Lansing, MI 48824, USA

${ }^{2}$ Chemistry, Michigan State University, East Lansing, MI 48824, USA

3 Department of Statistics and Probability, Michigan State University, East Lansing, MI 48824, USA

${ }^{4}$ Biochemistry and Molecular Biology, Michigan State University, East Lansing, MI 48824, USA

* Correspondence: kramerd8@msu.edu

Summary. The responses of plant photosynthesis to rapid fluctuations in environmental conditions are thought to be critical for efficient capture of light energy. Such responses are not well represented under laboratory conditions, but have also been difficult to probe in complex field environments. We demonstrate an open science approach to this problem that combines multifaceted measurements of photosynthesis and environmental conditions, and an unsupervised statistical clustering approach. In a selected set of data on mint (Mentha sp.), we show that the "light potential" for increasing linear electron flow (LEF) and nonphotochemical quenching (NPQ) upon rapid light increases are strongly suppressed in leaves previously exposed to low ambient PAR or low leaf temperatures, factors that can act both independently and cooperatively. Further analyses allowed us to test specific mechanisms. With decreasing leaf temperature or PAR, limitations to photosynthesis during high light fluctuations shifted from rapidly-induced NPQ to photosynthetic control (PCON) of electron flow at the cytochrome $b_{\sigma} f$ complex. At low temperatures, high light induced lumen acidification, but did not induce NPQ, leading to accumulation of reduced electron transfer intermediates, a situation likely to induce photodamage, and represents a potential target for improving the efficiency and robustness of photosynthesis. Finally, we discuss the 
implications of the approach for open science efforts to understand and improve crop productivity.

Keywords: nonphotochemical quenching (NPQ), photodamage, proton motive force, $\mathrm{qE}$, photosynthetic control, unsupervised learning

\section{Introduction}

While oxygenic photosynthesis supplies energy to drive essentially all biology in our ecosystem, it involves highly energetic intermediates that can generate highly toxic reactive oxygen species (ROS) that can damage the organisms it powers [1]. Thus, the energy input into photosynthesis must be tightly regulated by photoprotective mechanisms that act at several key steps in the light reactions. The balance and kinetics of this regulation is an active target for crop improvement.

One class of photoprotective processes, known as nonphotochemical quenching (NPQ), dissipates absorbed light energy as heat, thus diverting energy away from photosystem II (PSII) [2], decreasing the accumulation of reactive intermediates. This photoprotective capacity comes at the cost of decreased photochemical efficiency, and thus the organisms must regulate NPQ to balance the avoidance of photodamage with efficient energy conversion $[3,4]$. There are several forms of NPQ that differ in their mechanisms and rates of activation and deactivation. The most rapid NPQ form is $\mathrm{qE}$, which is activated by acidification of the thylakoid lumen by the proton gradient $(\Delta \mathrm{pH})$ component of the thylakoid proton motive force $(p m f)$ [2]. Lumen acidification activates the violaxanthin deepoxidase or VDE [5-8] resulting in the conversion of violaxanthin $(\mathrm{Vx})$ to antheraxanthin (Ax) and zeaxanthin (Zx); and protonation of PsbS, an antenna-associated protein required for $\mathrm{qE}$ [2], which appear to act cooperatively in setting the extent of $\mathrm{qE}$. The conversion of $\mathrm{Vx}$ to $\mathrm{Ax}$ and to $\mathrm{Zx}$ is typically much slower than the rapidly reversible protonation of PsbS [2], and during prolonged illumination, the responses of $\mathrm{qE}$ will likely be limited by the rate of acidification and de-acidification of the thylakoid lumen, which are, in turn, governed by ion movements in the chloroplasts [9-11]. Slower forms of NPQ have also been demonstrated [12], including $\mathrm{qI}$, which is related to the photodamage and repair of photosystem II (PSII) or qZ, which related to the accumulation of Zx 
(independently from qE) [13], qH, related to cold and high light stress [13], and qT, related to antenna state transitions [14].

The acidification of the thylakoid lumen also controls electron transfer at the cytochrome $b_{6} f$ complex, a process called photosynthetic control (PCON) [15-20], which prevents the buildup of electrons on the acceptor side of photosystem I (PSI) that can lead to photodamage $[15,21-23]$. Interestingly, $\mathrm{PCON}$ and $\mathrm{qE}$ (both responses to lumen acidification) are expected to have opposing effects on $\mathrm{Q}_{\mathrm{A}}$ redox state. High levels of PCON in the absence of $\mathrm{qE}$ would lead to accumulation of plastoquinol $\left(\mathrm{PQH}_{2}\right)$ and the reduced form of the PSII electron acceptor, $\mathrm{Q}_{\mathrm{A}^{-}}$, which can potentiate photodamage. Thus, these two processes must be tightly coordinated, with qE being activated at lumen $\mathrm{pH}$ somewhat less acidic than PCON [15].

Plants in natural environments are exposed to rapidly changing environmental conditions, especially light which can change by orders of magnitude in less than a second. It has become clear that rapid and unpredictable fluctuations in light intensity can be more damaging than more gradual changes [22,24-31]. This sensitivity can partly be related to the buildup of reactive redox intermediates and thylakoid pmf, which can occur following low-to-high light transitions much more rapidly than the activation of photoprotective NPQ and PCON, leaving the photosynthetic apparatus prone to photodamage. Also, the slow recovery of NPQ following a decrease in light intensity can lead to substantial losses of photosynthetic efficiency [32]. Recently, it has been reported that engineering plants with increased expression levels of VDE and zeaxanthin epoxidase (ZE), resulted in accelerated formation and reversal of qE accompanied by increased plant productivity [3], suggesting that it may be possible to increase yield in crops by modifying photosynthetic regulatory responses.

On the other hand, we lack comprehensive surveys of the range of natural response of photosynthesis to real environmental fluctuations, in part because of a lack of deployable scientific equipment and methods to probe these processes in the field. Consequently, it has not been possible to assess the mechanistic bases of extant natural variations in these processes, their possible benefits or tradeoffs, or which of these may be most useful for crop improvement. 
Here, we introduce a method and proof-of-concept field data results to address the following questions: Can we assess the extent of natural variations in rapid responses to fluctuations in photosynthetically-active radiation (PAR) intensity for both electron flow and photoprotection? How do these limitations depend on environmental conditions? What are the mechanisms that underlie these variations in responses to rapidly fluctuating light in the field?

Here, we introduce an approach to both measure and analyse these variations, focusing on one species, Mentha sp., under a limited set of conditions, and applied these to testing among a set of mechanisms that can be distinguished based on a range of optical measurements available using the MultispeQ 2.0 device, including: 1) PSI acceptor-side limitations to electron transfer; 2) Increased NPQ which limits the input of light energy into photosystem II (PSII); and 3) Photosynthetic control in which acidification of the lumen slows electron transfer at the level of plastoquinol $\left(\mathrm{PQH}_{2}\right)$ oxidation by the cytochrome $b_{6} f$ complex.

The results show that the approach can effectively be used to assess the range of variations in 'light potentials,' the extent to which increased light leads to increased photosynthetic responses, under field conditions, as well as to test specific hypothetical models, setting up a broad-scale, multiple participant, open science approach to exploring the responses across multiple species, genotypes and environments. The results also reveal, at least in Mentha, unexpected leaf temperature-dependent limitations in the rapid formation of NPQ that result in the accumulation of reduced PSII electron acceptor, $\mathrm{Q}_{\mathrm{A}}$ and a high thylakoid pmf, conditions likely to promote the formation of reactive oxygen species.

\section{Materials and Methods}

\section{Plants and leaf sampling.}

Measurements were made in a population of Mentha sp. (mint) plants that have been maintained at the MSU Horticulture Gardens for at least 10 years. The GPS locations of all measurements are included in the online data set (https://photosynq.org/projects/rapid-ps-responses-pam-ecst-npqt-mint-dmk). Although it was not practical to exhaustively capture the lifecycle of the plants, the experimental 
strategy sampled a sufficiently wide range of conditions to allow clear patterns emerged in the relationships between phenotypes and environmental parameters, as described below. The experiment took place over a nine-day experimental window (Figure S1A), sampling a range of times of day, temperatures etc. (Fig. S1B). Measurements were made at multiple, alternating canopy levels and positions (subjectively at high, middle and low canopy levels) from early morning, though later afternoon (Fig. S1B), and at multiple locations across the plots on each day.

\section{Measurements of photosynthetic and related parameters using MultispeQ 2.0.}

Optical measurements were made using MultispeQ V2.0 hand-held instruments (https://photosynq.com), based on that presented by Kuhlgert et al [33] and calibrated using the CaliQ calibration system (https://photosynq.com/caliq). The Light Potential (LP) protocol used in the experiments can be found in the online project information (rapid-ps-responses-with-ecs-fast-ecs-dirk-and-npqt-dmk) as illustrated in Figure 1. The protocol was designed to strike a balance between needs for sampling large numbers of leaves, the desire for detailed spectroscopic measurements and the length of time the plant could be exposed to increased or decreased PAR. The full protocol, with measurements at ambient, after $10 \mathrm{~s}$ full sunlight and $10 \mathrm{~s}$ dark required about $35-40 \mathrm{~s}$, at the limit of the time scale over which most researchers could steadily clamp a leaf in the instrument. The implications of the $10 \mathrm{~s}$ illumination and recovery time are discussed in the Results and Discussion sections.

In the first stage of the protocol (Fig. 1A), the MultispeQ was programmed to continuously (at about $5 \mathrm{~Hz}$ ) measure photosynthetically-active radiation (PAR) and reproduced these levels using a red actinic LED (655 $\mathrm{nm}$ emission peak) illuminating the adaxial surface of the leaf. When the MultispeQ detected that a leaf was clamped in the chamber, a series of measurement sequences were initiated. After a few seconds of illumination at ambient PAR $\left(\mathrm{PAR}_{\mathrm{amb}}\right)$ to allow for settling and setting of gains, the first set of measurements was made, estimating at $\mathrm{PAR}_{\mathrm{amb}} \mathrm{LEF}\left(\mathrm{LEF}_{\mathrm{amb}}\right)$, NPQt $\left(\mathrm{NPQ}_{\mathrm{amb}}\right)$ and other photosynthetic parameters (Fig. 1B). 


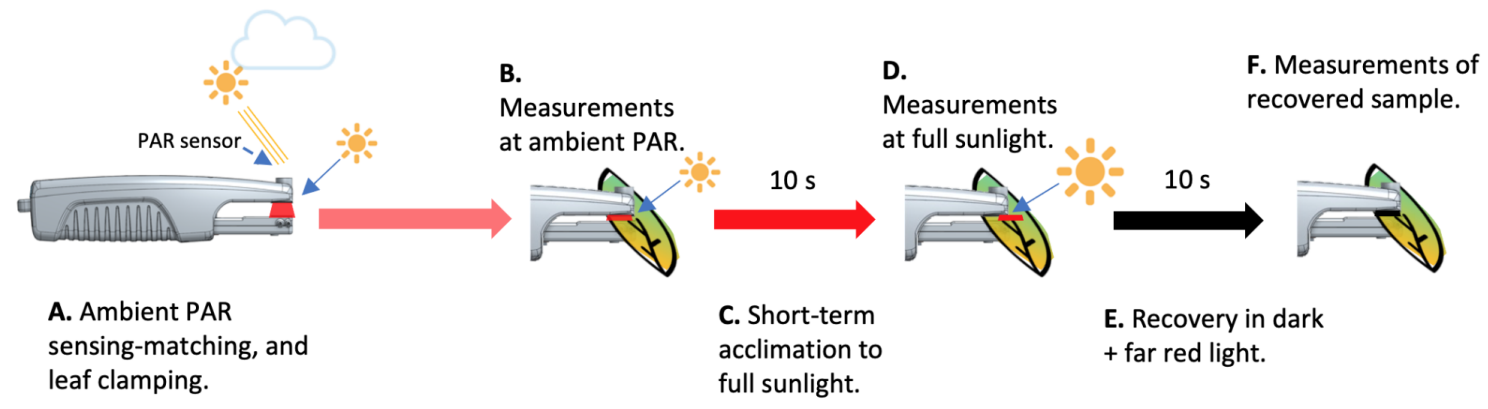

Figure 1. Experimental procedure of NPQ Light Potential designed to detect the change in NPQ induced under different light intensities. A) A sensor on the MultispeQ continuously detects the ambient photosynthetically active radiation (PAR) in the field and reproduces this PAR value using internal LED. B)When the leaf clamp is closed over a leaf, the experiment begins by recording the local PAR, leaf temperature, ambient temperature, leaf angle and GPS position. After a short period of illumination at the measured ambient PAR, the first set of optical measurement are recorded. C) Once completed, the leaf is exposed to a period of high PAR $\left(2,000 \mu \mathrm{mol} \cdot \mathrm{m}^{-2} \cdot \mathrm{s}^{-1}\right.$, equivalent to full sunlight) for $10 \mathrm{~s}$. D) The optical measurements are repeated at high PAR. E) The leaf is then dark adapted (actinic light is switched off), with weak far red background light for $10 \mathrm{~s}$ (Panel E). F) A final set of optical measurements is made to assess rapid dissipation of NPQ and reoxidation of accumulated reduced intermediates. Each set of optical measurements includes chlorophyll fluorescence and absorbance changes to give estimates of $\phi_{I I}, L E F, N P Q t, q_{L}\left(Q_{A}\right.$ redox state); ECSt, $\mathrm{P}_{700}$ redox state, and $\mathrm{g}_{\mathrm{H}^{+}}$(relative proton conductivity of the thylakoid ATP synthase), as described in Materials and Methods. Measurements taken at ambient and light are designated as "measurement (ambient), LEF (ambient), NPQt (ambient), $\mathrm{q}_{\mathrm{L}}$ (ambient).

The actinic light was then increased to approximately full sunlight $\left(2,000 \mu \mathrm{mol} \cdot \mathrm{m}^{-2} \cdot \mathrm{s}^{-1} \mathrm{red}\right.$ light) for $10 \mathrm{~s}$ (Fig. $1 \mathrm{C}$ ), after which the photosynthetic measurements were repeated (Fig 1D), yielding measurements of $\mathrm{LEF}_{\text {high }}, \mathrm{NPQ}_{\text {high }}$ etc. We chose full sunlight, rather than an artificially intense super-saturation light, to estimate light potentials that could occur in the field, and not the absolute maximum, and to avoid non-physiological or photoinhibitory effects. Thus, the light potentials of various processes will be limited as $\mathrm{PAR}_{\mathrm{amb}}$ approaches full sunlight.

In the third stage of the experiment, the actinic light was then switched off, and a weak far-red light switched on for 10s (Fig. 1E), following another repetition of the measurements to assess the extent of $\mathrm{NPQ}_{\mathrm{t}}$ after relaxation $\left(\mathrm{NPQ}_{\text {rec }}\right.$, Fig. 1F). Environmental parameters including PAR, temperature, humidity, leaf temperature, leaf 
angle and GPS location were measured either prior to or following the physiological measurements.

Chlorophyll fluorescence changes were measured using MultispeQ 2.0 devices to estimate PSII quantum efficiency $\left(\Phi_{\text {III }}\right)$ and linear electron flow (LEF) [34,35], as well as qL, a measure of the fraction of $Q_{A}$ in the oxidised state [36], and the extent of NPQ based on the rapid "total" NPQ method developed by Tietz et al. [37], designated as NPQ. Just prior to the saturation pulses, dark interval relaxation kinetics (DIRK, dark interval of approximately $300 \mathrm{~ms}$ ) of the absorbance changes around $520 \mathrm{~nm}$ attributed to the electrochromic shift (ECS) were recorded. Fitting the ECS signals to exponential decay curves yielded estimates of the relative light-dark differences in thylakoid $p m f\left(\mathrm{ECS}_{\mathrm{t}}\right)$ and the proton conductivity of the chloroplast ATP synthase $\left(g_{\mathrm{H}^{+}}\right)$, as described in $[16,38,39]$. To account for differences in leaf thickness, light path or number of chloroplasts in various leaves, the $\mathrm{ECS}_{\mathrm{t}}$ values were normalised to the relative chlorophyll contents as estimated by the SPAD parameter [33], which was measured at the end of the experiment. The extent of oxidation of $\mathrm{P}_{700}$ in the light was estimated by the DIRK of infrared LED light using an LED measuring pulse with peak emission at $\sim 810 \mathrm{~nm}$.

\section{Environmental conditions during light potential measurements in the field.}

Supplemental figures S1A-C show the distributions of environmental factors (light intensities, leaf temperatures) for the measurements analyzed in this study. The MultispeQ sensor was positioned by the user to be parallel to the leaf surface, so that the cosine-corrected PAR sensor should effectively estimate PAR absorbed by the leaf surfaces in situ throughout their canopy, and thus the ambient PAR $\left(\mathrm{PAR}_{\mathrm{amb}}\right)$ values were dependent on both time of day (diurnal cycle, Fig. S1B) and by leaf angle (Fig. S1C). Ambient temperature and leaf temperatures $\left(\mathrm{T}_{\text {leaf }}\right)$ were dependent on time of day, with obvious influences from weather-related fluctuations (Fig. S1A, B). We chose to compare results to $\mathrm{T}_{\text {leaf }}$, rather than ambient temperature, to better reflect the effects on leaf photosynthetic processes.

\section{Data calculations and cleaning}


Data from the PhotosynQ platforms was reprocessed and cleaned to improve the estimation of decay constants for electrochromic shift and near infrared absorbance changes. As with any field experiments, some results were found to have obvious errors or be out of acceptable ranges, and were removed from the analysis. However, all original data was maintained in the online platform, allowing the reader to explore and reanalyse the effects of our data cleaning procedures. The rules and code for data flagging are defined in the Jupyter Notebook, (see Supplemental Information, “Data Cleaning Notebook"). A total of 292 points were flagged from a total of 1346 original measurements. The majority of the flagged measurements (179) were due to a defective device. The remaining 113 flagged points can be attributed to user error (e.g. leaf movements during measurements) or poor signal-to-noise that resulted in parameter values outside the theoretical ranges.

\section{Results}

Field measurements of photosynthetic parameters under ambient and rapidly elevated PAR.

Figure 2A shows LEF measured at $\mathrm{PAR}_{\mathrm{amb}}\left(\mathrm{LEF}_{\mathrm{amb}}\right)$ plotted against ambient $\mathrm{PAR}_{\mathrm{amb}}$ and leaf temperature ( $\mathrm{T}_{\text {leaf }}$, see colouration of points). The plots use the square root of PAR to better resolve the results at lower $\mathrm{PAR}_{\mathrm{amb}}$, and to partially linearise the responses. $\mathrm{LEF}_{\mathrm{amb}}$ increased with increasing $\mathrm{PAR}_{\mathrm{amb}}$, with a roughly hyperbolic dependence and an apparent half-saturation point of about $350 \mu \mathrm{mol}$ photons $\mathrm{m}^{-2} \mathrm{~s}^{-1}$, reaching maximum values of about $250 \mu \mathrm{mol}$ electrons $\mathrm{m}^{-2} \mathrm{~s}^{-1}$ at $1700 \mu \mathrm{mol}$ photons $\mathrm{m}^{-2} \mathrm{~s}^{-1}$. 


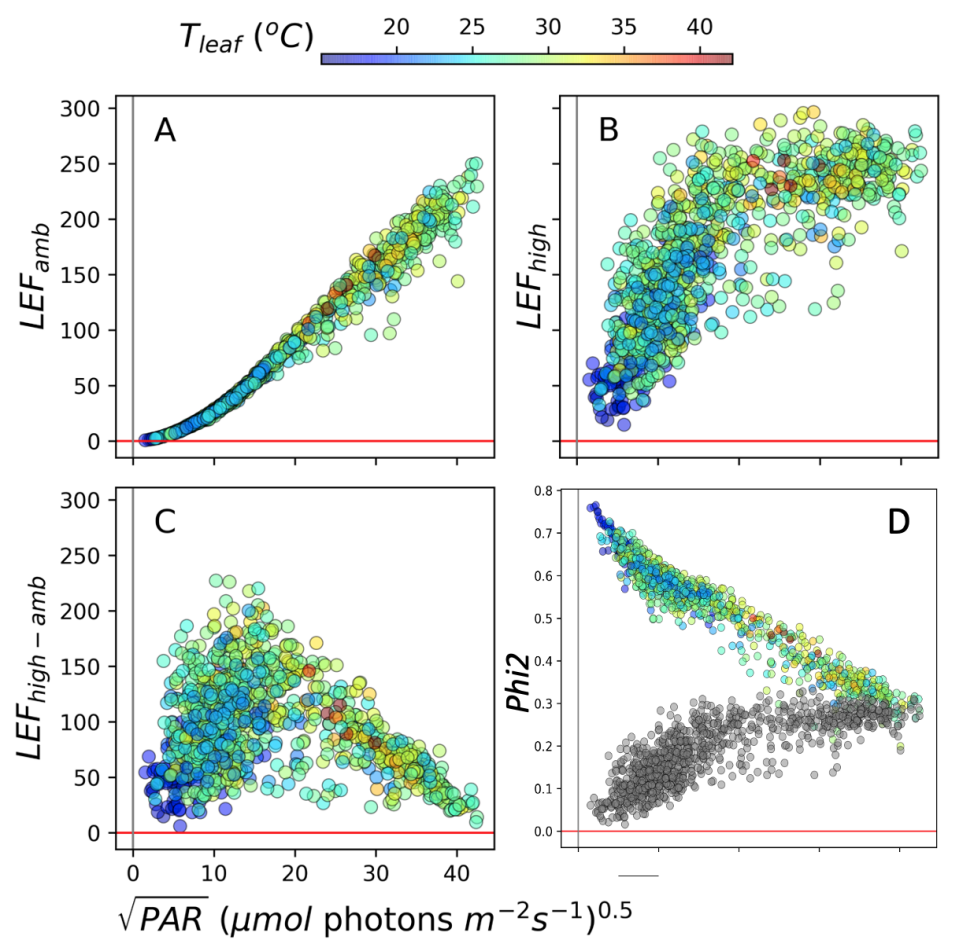

Figure 2. Light and temperature effects on linear electron flow (LEF) and Photosystem II quantum efficiency $\left(\Phi_{\text {II }}\right)$. Each parameter was plotted functions of the square root of the ambient photosynthetically active radiation $\left(\mathrm{PAR}_{\mathrm{amb}}, \mathrm{X}\right.$-axis) and Leaf Temperature ( $\mathrm{T}_{\text {leaf }}$, coloration of points). A) Dependencies of Linear Electron Flow (LEF) measured at $\mathrm{PAR}_{\mathrm{amb}}$; B) LEF measured at 10s high light $\left.\left(\mathrm{LEF}_{\text {high }}\right) ; \mathrm{C}\right)$ The high light-induced differences in LEF $\left.\left(\mathrm{LEF}_{\text {high-amb }}\right) ; \mathrm{D}\right)$ The PSII quantum efficiencies measured under ambient PAR (Phi2amb, points colored by $\left.\mathrm{T}_{\text {leaf }}\right)$ and at 10 s high light ( $\mathrm{Phi} 2_{\text {high }}$, grey points).

Upon ten seconds of exposure to $2000 \mu \mathrm{mol}$ photons $\mathrm{m}^{-2} \mathrm{~s}^{-1}$ increased LEF to generally higher values $\left(\mathrm{LEF}_{\text {high }}\right.$ Fig. $\left.2 \mathrm{~B}\right)$, indicating that $\mathrm{LEF}_{\mathrm{amb}}$ was at least partly light-limited under all of the conditions. Note that each $\mathrm{LEF}_{\mathrm{amb}}$ point was taken on different leaves at different times (Materials and Methods) and has corresponding $\mathrm{LEF}_{\text {high }}$ and $\mathrm{LEF}_{\text {high-amb }}$ measurements. The relationship between measurements is illustrated in Fig. S2, which shows selected pairs of $\mathrm{LEF}_{\mathrm{amb}}$ and $\mathrm{LEF}_{\text {high }}$ connected by vertical line segments. The extent of $\mathrm{LEF}_{\text {high }}$ was not uniform, but appeared to be strongly suppressed at low $\mathrm{PAR}_{\text {amb }}$ and/or low $\mathrm{T}_{\text {leaf }}$. The high light-induced difference in $\mathrm{LEF}\left(\mathrm{LEF}_{\text {high-amb }}\right)$ increased with $\mathrm{PAR}_{\text {amb }}$ at low light, reaching a peak at about $200 \mu \mathrm{mol}$ photons $\mathrm{m}^{-2} \mathrm{~s}^{-1}$, above which it declined as $\mathrm{PAR}_{\text {amb }}$ approached $\mathrm{PAR}_{\text {high }}$ and $\mathrm{LEF}_{\text {high }}$ became light-saturated. The suppression of $\mathrm{LEF}_{\text {high }}$ was due to large decreases in the quantum efficiencies of PSII (Phi2, Fig. 2D). Phi2 at $\mathrm{PAR}_{\text {amb }}\left(\mathrm{Phi}_{\mathrm{amb}}\right)$ were highest at low $\mathrm{PAR}_{\mathrm{amb}}$, and progressively saturated as light was increased. The opposite behavior was seen with Phi2 measured after 10s of high light 
(Phi $2_{\text {high }}$ Fig. 2D, grey symbols) which was lowest at low PAR $_{\text {amb }}$, and gradually increased with PAR amb

\section{Gaussian Mixture Model clustering analysis of field data}

A simple linear effects model applied over the entire data set (Supplemental Table S1A) indicated strong correlations between $\mathrm{LEF}_{\mathrm{amb}}$ and both $\mathrm{PAR}_{\mathrm{amb}}$ and $\mathrm{T}_{\text {leaf }}$, suggesting that both environmental factors controlled $\mathrm{LEF}_{\mathrm{amb}}$. However, such correlations may be coincidental since PAR and $\mathrm{T}_{\text {leaf }}$ are both expected to be dependent on weather or time of day, as it is clear from the strong statistical correlations between PAR and $\mathrm{T}_{\text {leaf }}$. Also, the effects are likely to be co-dependent. For example, at low $\mathrm{PAR}_{\mathrm{amb}}, \mathrm{LEF}_{\mathrm{amb}}$ should be light-limited, and thus have minimal dependence on $\mathrm{T}_{\text {leaf }}$, but at higher $\mathrm{PAR}_{\mathrm{amb}}$, may be more strongly controlled by temperature-dependent processes.

One approach to disentangling these effects would be to slice the data into segments, e.g., at different ranges of $\mathrm{PAR}_{\mathrm{amb}}$, and test for correlations with $\mathrm{T}_{\text {leaf }}$ within each segment. However, arbitrary-chosen ranges for the segments can add bias, or fail to detect more complex interactions. We thus applied a Gaussian Mixture Model (GMM) clustering approach based on those presented earlier [40,41]. Because GMM is an unsupervised machine learning method, it can reduce bias in the selection of clusters that represent regions of distinct interactions among environmental and photosynthetic parameters. GMM assumes that the data points from the population of interest are being drawn from a combination (or mixture) of Gaussian distributions with certain parameters, and performs an optimization scheme to a sum of K Gaussian distributions, allowing for a completely unsupervised process, avoiding potential user bias. An expectation-maximization (EM) algorithm was used to fit the GMM to the dataset, generating a series of Gaussian components (clusters) with distributions characterised by specific means and covariance matrices. The optimal number of clusters was determined using the Bayesian Information Criterion (BIC), the value of the maximised log likelihood, with a penalty on the number of parameters in the model [40-43]. This approach also allows comparison of models with differing parameterizations and/or differing numbers of clusters, because the volumes, shapes, and orientations of the covariances can be constrained to those described by defined models [40]. 
Clusters obtained through GMM have both within cluster (intracluster) and between cluster (intercluster) variations. In order to test for intercluster variation, we used the clustering assignment obtained for one phenotype and applied it on other phenotype(s). Here we want to investigate what would be the distinctive behaviour of different phenotypes if we have used the same configuration. Using the same set of cluster assignments to different phenotypes, one might be skeptical of the clustering behaviour as phenotypes interact differently with $\mathrm{PAR}_{\mathrm{amb}}$ and $\mathrm{T}_{\text {leaf }}$. In that case, we might not be able to directly compare the inter cluster behaviours of phenotypes. To mitigate this issue, we use the GMM clustering as a tool to create a "baseline" clustering configuration for one phenotype and use that configuration over another phenotype. We set up our hypothesis as two phenotypes are similar under the same configuration against they are not. If the interaction pattern of one phenotype with $\mathrm{PAR}_{\mathrm{amb}}$ and $\mathrm{T}_{\text {leaf }}$ changes over the other phenotype, we reject our hypothesis and imply that different configurations of $\mathrm{PAR}_{\mathrm{amb}}$ and $\mathrm{T}_{\text {leaf }}$ interact differently with phenotypes. By doing this we are able to disentangle the effect of $\mathrm{PAR}_{\mathrm{amb}}$ and $\mathrm{T}_{\text {leaf }}$ and infer regarding the intracluster variations as to be a key element to determine variations in the interactions between parameters and variations in environmental conditions, e.g., to assess if a relationship is modulated in different ways under different ranges of conditions. Also, as will be seen in the Discussion, intercluster variations (differences in the mean and covariances between clusters) can be used to differentiate distinct patterns of behavior, or mechanistic interactions, between conditions.

As shown in Fig. S3, GMM analysis of $\mathrm{LEF}_{\mathrm{amb}}, \mathrm{PAR}_{\mathrm{amb}}$ and $\mathrm{T}_{\text {leaf, }}$, found six distinct, compact clusters that differed in the mode of interaction among the photosynthetic and environmental parameters. Encompassing points with lower PAR $\mathrm{amb}_{\mathrm{am}}$ showed strong (Clusters 1,2,4 and 5) dependence of $\mathrm{LEF}_{\mathrm{amb}}$ on $\mathrm{PAR}_{\mathrm{amb}}$, with little contributions from $\mathrm{T}_{\text {leaf. }}$. By contrast, two clusters (3 and 6), which included points at higher PAR $_{\text {amb }}$, showed substantial dependencies on both $\mathrm{PAR}_{\mathrm{amb}}$ and $\mathrm{T}_{\text {leaf }}$. These results are consistent with LEF being predominantly light-limited at low ambient PAR, but increasingly limited by temperature-dependent processes at higher PAR. The presence of these two classes of clusters indicates that $\mathrm{PAR}_{\mathrm{amb}}$ and $\mathrm{T}_{\text {leaf }}$ are likely to affect $\mathrm{LEF}_{\mathrm{amb}}$ in independent ways. The fact that the shapes of the clusters were not determined with individual slicing under the individual parameters for $\mathrm{PAR}_{\mathrm{amb}}$ and $\mathrm{T}_{\text {leaf }}$, but with a co-dependence on both $\mathrm{PAR}_{\mathrm{amb}}$ and $\mathrm{T}_{\text {leaf }}$, suggests that, under some conditions, these effects interact, e.g. $\mathrm{T}_{\text {leaf }}$ may affect the dependence of $\mathrm{LEF}_{\mathrm{amb}}$ on $\mathrm{PAR}_{\mathrm{amb}}$. 
GMM identified five distinct clusters for interactions among $\mathrm{LEF}_{\text {high }}, \mathrm{PAR}_{\mathrm{amb}}$ and $\mathrm{T}_{\text {leaf }}$ (Fig. S4). In contrast to the results on $\mathrm{LEF}_{\mathrm{amb}}$, clusters at lower $\operatorname{PAR}_{\mathrm{amb}}(1,2$ and 4) showed $\mathrm{LEF}_{\text {high }}$ dependencies on both $\mathrm{T}_{\text {leaf }}$ and $\mathrm{PAR}_{\mathrm{amb}}$, while Cluster 3 showed correlations with $\mathrm{T}_{\text {leaf }}$, but not with $\mathrm{PAR}_{\mathrm{amb}}$. The stronger dependence on $\mathrm{T}_{\text {leaf }}$ of $\mathrm{LEF}_{\text {high }}$ compared to $\mathrm{LEF}_{\mathrm{amb}}$ implies that the exposure to high light revealed additional rate limitations in $\mathrm{LEF}_{\text {high }}$ that were more strongly controlled by both $\mathrm{T}_{\text {leaf }}$ and $\mathrm{PAR}_{\mathrm{amb}}$ and that, at least under some conditions, these effects were independent of each other.

\section{Analysis of NPQ}

$\mathrm{NPQ}_{\mathrm{t}}$ measured under $\mathrm{PAR}_{\mathrm{amb}}\left(\mathrm{NPQ}_{\mathrm{amb}}\right.$, Fig. 3A) showed a positive correlation to $\mathrm{PAR}_{\mathrm{amb}}$, with an apparent tendency for smaller values at lower $\mathrm{T}_{\text {leaf }}$ NPQ $\mathrm{Namb}_{\mathrm{b}}$ showed considerable variations, compared to $\mathrm{LEF}_{\mathrm{amb}}$, even at low $\mathrm{PAR}_{\mathrm{amb}}$, consistent with the idea that NPQ is governed not only by PAR but by metabolic, developmental or other environmental parameters.

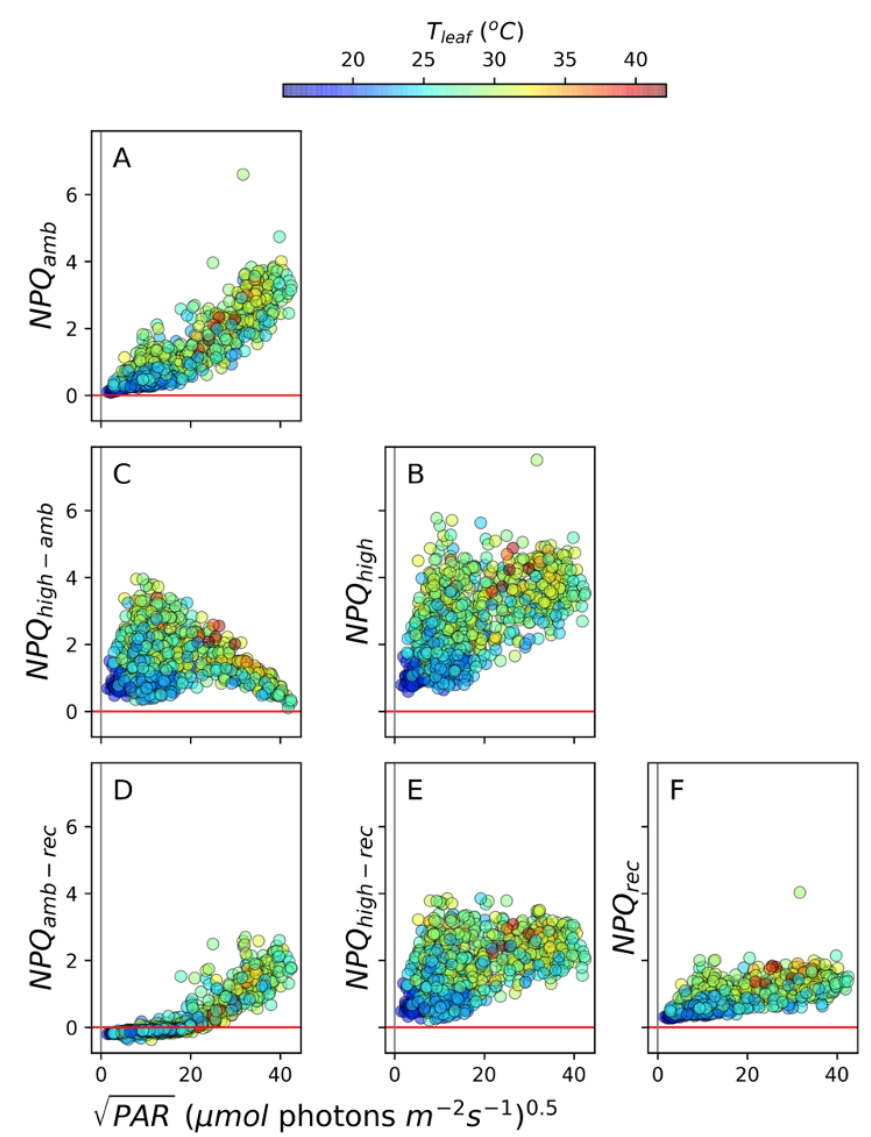


Figure 3. Light and temperature effects on NPQ. The NPQ parameter was plotted functions of the square root of the ambient photosynthetically active radiation $\left(\mathrm{PAR}_{\mathrm{amb}}, \mathrm{X}\right.$-axis) and Leaf Temperature ( $\mathrm{T}_{\text {leaf }}$, coloration of points). A) Induced NPQ measured at $\mathrm{PAR}_{\mathrm{amb}}$; B) NPQ measured at $10 \mathrm{~s}$ high light $\left(\mathrm{NPQ}_{\text {high }}\right)$; C) The high light-induced differences in NPQ $\left(\mathrm{NPQ}_{\text {high-amb }}\right)$; D) The difference in induced NPQ level at ambient PAR and the 10s recovery time in the dark $\left(\mathrm{NPQ}_{\mathrm{amb}}\right.$ ${ }_{\mathrm{rec}}$ ); E) The difference in induced NPQ level at $10 \mathrm{~s}$ high PAR and the 10 s recovery time in the dark $\left.\left(\mathrm{NPQ}_{\text {high-rec }}\right) ; \mathrm{F}\right)$ the NPQ level after $10 \mathrm{~s}$ in the dark $\left(\mathrm{NPQ}_{\mathrm{rec}}\right)$.

Figure 3B shows $\mathrm{NPQ}_{\mathrm{t}}$ values measured at 10 s full sunlight $\left(\mathrm{NPQ}_{\text {high }}\right)$. The NPQ light potential, or light-induced differences in NPQ $\left(\mathrm{NPQ}_{\text {high-amb }}\right)$ are shown in Fig. 3C. While $\mathrm{NPQ}_{\text {high-amb }}$ was always positive, both $\mathrm{NPQ}_{\text {high-amb }}$ and $\mathrm{NPQ}_{\text {high }}$ were suppressed at low $\mathrm{PAR}_{\mathrm{amb}}$ or $\mathrm{T}_{\text {leaf. }} \mathrm{NPQ}_{\mathrm{t}}$ measured after the $10 \mathrm{~s}$ dark recovery period $\left(\mathrm{NPQ}_{\text {rec }}\right.$, Fig. $\left.3 \mathrm{~F}\right)$ was consistently lower than $\mathrm{NPQ}_{\mathrm{amb}}$ and $\mathrm{NPQ}_{\text {high }}$. The difference between $\mathrm{NPQ}_{\mathrm{amb}}$ and $\mathrm{NPQ}_{\mathrm{rec}}$ $\left(\mathrm{NPQ}_{\mathrm{amb}-\mathrm{rec}}\right.$, Fig. 3D) ranged from slightly negative at low $\mathrm{PAR}_{\mathrm{amb}}$, where the majority of $\mathrm{NPQ}_{\mathrm{amb}}$ was rapidly reversible, to about one at the higher $\mathrm{PAR}_{\mathrm{amb}}$, where about half of $\mathrm{NPQ}_{\mathrm{amb}}$ was rapidly reversed.

Overall, these results indicate that the majority of $\mathrm{NPQ}_{\mathrm{amb}}$ as well $\mathrm{NPQ}_{\text {high }}$ recovered within $10 \mathrm{~s}$ of darkness and can likely be attributed to $\mathrm{qE}$, and thus, under our conditions, $\mathrm{qE}$ is likely to be the most important form of NPQ. The residual, more slowly reversible, components reaching a little above 2 are likely to include qI or qZ [44,45], although the limited time frame for the protocol does not allow us to rule out contributions from longer-lived $\mathrm{qE}$.

As with LEF, a simple linear effects model (Table S1B) showed strong interactions between $\mathrm{T}_{\text {leaf }}$ and $\mathrm{PAR}_{\mathrm{amb}}$, on $\mathrm{NPQ}_{\mathrm{amb}}$ and the corresponding GMM analysis identified four clusters (Fig. S5). Cluster 1, which encompassed the lowest range of $\mathrm{PAR}_{\text {amb }}$ values, showed strong dependence on $\mathrm{PAR}_{\mathrm{amb}}$, with no significant dependence on $\mathrm{T}_{\text {leaf }}$. The remaining clusters showed either dependence solely on $\mathrm{T}_{\text {leaf }}\left(\right.$ Cluster 4 ) or codependence on $\mathrm{PAR}_{\text {amb }}$ and $\mathrm{T}_{\text {leaf }}$ (Clusters 2 and 3). Because GMM clustering suggests that $\mathrm{T}_{\text {leaf }}$ and $\mathrm{PAR}_{\mathrm{amb}}$ can interact or act independently, depending on conditions, we excluded the linear effects models and focused on GMM for analyses of the remaining parameters.

For the analysis of $\mathrm{NPQ}_{\text {high }}$ (Fig. S6), we used the clusters found for $\mathrm{NPQ}_{\mathrm{amb}}$ (Fig. S5), allowing us to directly compare changes in correlations among parameters within each 
cluster [40]. Cluster 1, which encompassed the lowest range of $\mathrm{PAR}_{\mathrm{amb}}$ values, showed strong dependence of $\mathrm{NPQ}_{\text {high }}$ on both $\mathrm{PAR}_{\mathrm{amb}}$ and $\mathrm{T}_{\text {leaf. }}$ This pattern of dependencies was in contrast to that for Cluster 1 for $\mathrm{NPQ}_{\mathrm{amb}}$, which showed dependence solely on $\mathrm{PAR}_{\mathrm{amb}}$. At a higher range of $\mathrm{PAR}_{\mathrm{amb}}$ (Cluster 3), $\mathrm{NPQ}_{\text {high }}$ showed significant dependence solely on $\mathrm{T}_{\text {leaf }}$, again in contrast to the corresponding cluster for $\mathrm{NPQ}_{\mathrm{amb}}$, which showed dependencies on both $\mathrm{PAR}_{\mathrm{amb}}$ and $\mathrm{T}_{\text {leaf }}$ Overall, compared to $\mathrm{NPQ}_{\mathrm{amb}}, \mathrm{NPQ}_{\text {high }}$ showed increased dependence on $\mathrm{T}_{\text {leaf }}$ in all clusters, suggesting that it is more substantially controlled by metabolic or physiological factors (see Discussion).

\section{The redox state of $Q_{A}$}

Figure $4 A$ shows the dependencies of $\mathrm{Q}_{\mathrm{A}}$ redox state $(\mathrm{qL})$ on PAR and $\mathrm{T}_{\text {leaf }}$. $\mathrm{qL}$ measured at $\operatorname{PAR}_{\mathrm{amb}}\left(\mathrm{qL}_{\mathrm{amb}}\right.$, Fig. 4A), was relatively constant (ranging from about 0.3 to 0.75 ) across

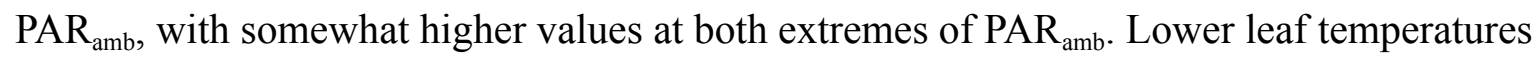
appeared to be associated with lower $\mathrm{qL}$ values, over the entire range of $\mathrm{PAR}_{\mathrm{amb}}$, although the effect was particularly pronounced at low light. By contrast, qL measured at 10s of high light ( $\mathrm{qL}_{\text {high }}$, Fig. 4B) showed strong dependence on $\mathrm{PAR}_{\mathrm{amb}}$, ranging from near zero (fully reduced $\mathrm{Q}_{\mathrm{A}}$ ) at low $\mathrm{PAR}_{\mathrm{amb}}$, to almost one (fully oxidised) at higher $\mathrm{PAR}_{\mathrm{amb}}$. Again, low $\mathrm{T}_{\text {leaf }}$ appeared to correlate with lower $\mathrm{qL}_{\text {high }}$ throughout the range of $\mathrm{PAR}_{\mathrm{amb}}$. Strikingly, as shown in Fig. 4C, the high light treatment induced two distinct effects: At low PAR $_{\text {amb }}$ and/or $T_{\text {leaf }}$, it induced a net reduction of $\mathrm{Q}_{\mathrm{A}}$, while it had the opposite effect at higher $\mathrm{PAR}_{\mathrm{amb}}$ and $\mathrm{T}_{\text {leaf }}$. 


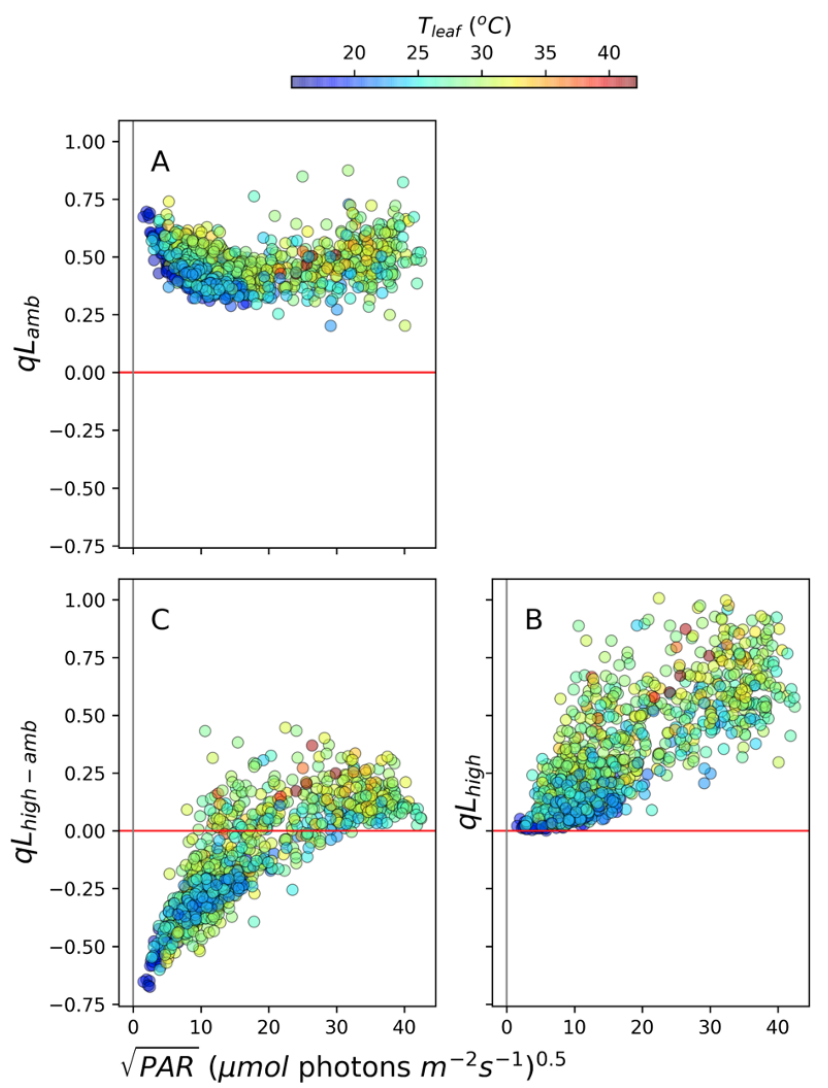

Figure 4. The light and temperature dependencies of the redox state of $\mathbf{Q}_{\mathbf{A}}$. The $\mathrm{qL}$ parameter, a measure of fraction of $\mathrm{Q}_{\mathrm{A}}$ in its oxidized state, was measured as described in Material and Methods, under ambient light $\left(\mathrm{qL}_{\mathrm{amb}}\right.$, Panel $\left.\mathrm{A}\right)$, at $10 \mathrm{~s}$ of high light ( $\mathrm{qL}_{\mathrm{high}}$, Panel $\left.\mathrm{B}\right)$, and the change in $\mathrm{qL}$ between high and ambient PAR ( $\mathrm{qL}_{\text {high-amb}}$, Panel $\mathrm{C}$ ) as a functions of the square root of ambient PAR.

GMM clustering for $\mathrm{qL}_{\mathrm{amb}}, \mathrm{PAR}_{\mathrm{amb}}$ and $\mathrm{T}_{\text {leaf }}$ (Fig. S7) identified four distinct clusters. In

Cluster 2, which encompasses points at low $\mathrm{PAR}_{\mathrm{amb}}$, significant associations were observed only between $\mathrm{qL}_{\mathrm{amb}}$ and $\mathrm{PAR}_{\mathrm{amb}}$. Clusters 1,3 and 4 (at higher $\mathrm{PAR}_{\mathrm{amb}}$ ) showed co-dependencies between $\mathrm{qL}_{\mathrm{amb}}$ and both $\mathrm{PAR}_{\mathrm{amb}}$ and $\mathrm{T}_{\text {leaf. }}$ GMM clustering for $\mathrm{qL}_{\text {high }}$, $\mathrm{PAR}_{\mathrm{amb}}$ and $\mathrm{T}_{\text {leaf }}$ showed five distinct clusters (Fig. S8). Clusters 1,2 and 5, which encompassed generally lower ranges for $\mathrm{PAR}_{\mathrm{amb}}$ and $\mathrm{T}_{\text {leaf }}$, showed $\mathrm{qL}_{\text {high }}$ dependencies on both $\mathrm{PAR}_{\mathrm{amb}}$ and $\mathrm{T}_{\text {leaf. }}$. Clusters 3 and 4 (generally with higher PAR $\mathrm{R}_{\mathrm{amb}}$ and $\mathrm{T}_{\text {leaf }}$ values) showed only dependencies on $\mathrm{T}_{\text {leaf. }}$. The overall pattern of cluster behaviour was similar to that observed with respect to $\mathrm{NPQ}_{\mathrm{amb}}$ and $\mathrm{NPQ}$ high

\section{P700 redox state}


Figure 5 shows the extent of oxidised $\mathrm{P}_{700}{ }^{+}\left(\mathrm{P}^{+}\right)$, based on the DIRK of absorbance changes at $810 \mathrm{~nm} . \mathrm{P}_{700}{ }^{+}$at $\mathrm{PAR}_{\mathrm{amb}}\left(\mathrm{P}^{+}{ }_{\text {amb }}\right.$, Fig. 5A), after ten seconds of high light $\left(\mathrm{P}^{+}\right.$high, Fig. 5B) and the light-induced difference $\left(\mathrm{P}^{+}\right.$high-amb, Fig. 5C). The extent of $\mathrm{P}^{+}{ }_{\text {amb }}$ was nearly linearly related to $\mathrm{PAR}_{\mathrm{amb}}$. Increasing the light resulted in higher $\mathrm{P}^{+}$values $\left(\mathrm{P}^{+}{ }_{\text {high }}\right)$, indicating that, in all cases, PSI became more oxidised at high light. The extent of the light-induced oxidation was dependent on $\mathrm{PAR}_{\mathrm{amb}}$, with lower extents at low $\mathrm{PAR}_{\mathrm{amb}}$, and a peak at about 200-300 $\mu \mathrm{mol}$ photons $\mathrm{m}^{-2} \mathrm{~s}^{-1}$. The decrease at higher $\mathrm{PAR}_{\mathrm{amb}}$ was probably due to the accumulation of pre-oxidised $\mathrm{P}_{700}$ prior to the high light treatment.

The full extent of $\mathrm{P}^{+}{ }_{\text {high }}$ was relatively constant over the conditions, suggesting that high light was able to nearly fully oxidise $\mathrm{P}_{700}$. However, there was a slight trend to lower $\mathrm{P}^{+}{ }_{\text {high }}$ at the highest $\mathrm{PAR}_{\mathrm{amb}}$ or $\mathrm{T}_{\text {leaf }}$, suggesting that total oxidizable PSI may have decreased at high light or temperatures, perhaps reflecting accumulation of PSI photodamage or electron sink limitations. Consistent with these general trends, GMM analyses of $\mathrm{P}^{+}{ }_{\mathrm{amb}}, \mathrm{PAR}_{\mathrm{amb}}$ and $\mathrm{T}_{\text {leaf }}$ identified four distinct clusters (Fig. S9), with dependencies on either PAR $_{\text {amb }}$ by itself (Clusters 3 and 4), or both $\mathrm{PAR}_{\mathrm{amb}}$ and $\mathrm{T}_{\text {leaf }}$ (Clusters 1 and 2). GMM clustering for $\mathrm{P}^{+}$high identified five distinct clusters (Fig. S10), that showed a positive dependency of $\mathrm{P}^{+}{ }_{\text {high }}$ on either $\mathrm{PAR}_{\mathrm{amb}}\left(\right.$ Cluster 1), or $\mathrm{T}_{\text {leaf }}\left(\right.$ Cluster 5), or a small, negative dependence on $\mathrm{T}_{\text {leaf }}$ (Cluster 3).

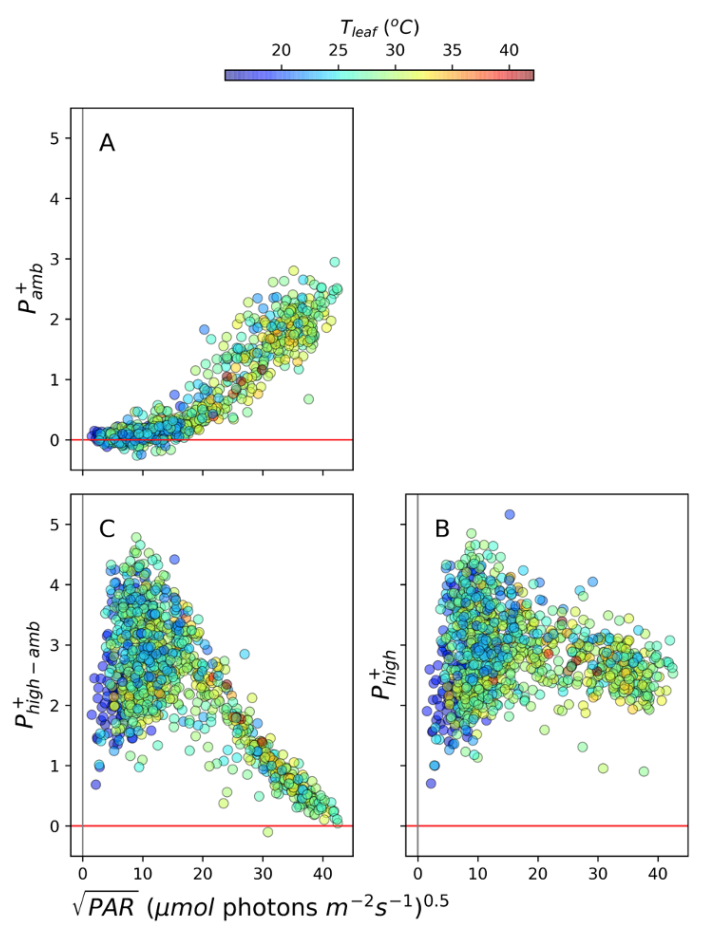


Figure 5. The light and temperature dependencies of the redox state of $\mathbf{P}_{700}+$. The redox state of $\mathrm{P}_{700}$ was measured using DIRK at $810 \mathrm{~nm}$ absorbance change under ambient light $\left(\mathrm{P}^{+}{ }_{\text {amb }}\right.$, Panel $\left.\mathrm{A}\right)$, at 10 s of high light $\left(\mathrm{P}^{+}\right.$high, Panel $\left.\mathrm{B}\right)$, and the change in $\mathrm{P}^{+}$between high and ambient PAR $\left(\mathrm{P}^{+}\right.$high-amb, Panel $\left.\mathrm{C}\right)$ as a functions of the square root of ambient PAR.

\section{ECSt and thylakoid pmf}

Figure 6 shows dependencies of relative thylakoid $p m f$, estimated by normalised ECSt measurements, at ambient PAR (ECSt $t_{\text {amb }}$, Fig. 6A) and after 10s exposure to high light $\left(\mathrm{ECSt}_{\text {high }}\right.$, Fig. 6B). The high light-induced differences $\left(\mathrm{ECSt}_{\text {high-amb }}\right)$ are shown in Fig. 6C. $\mathrm{ECSt}_{\mathrm{amb}}$ showed strong, positive correlations with $\mathrm{PAR}_{\mathrm{amb}}$, similar to the responses of $\mathrm{NPQ}_{\mathrm{amb}}$ (Fig. 3A) and $\mathrm{P}^{+}$amb $\left(\right.$Fig. 5A). ECSt ${ }_{\text {high }}$ values were, in general, larger than $\mathrm{ECSt}_{\mathrm{amb}}$, resulting in positive values for $\mathrm{ECSt}_{\text {high-amb. }}$ At low $\mathrm{PAR}_{\mathrm{amb}}, \mathrm{ECSt}_{\text {high }}$ showed high variability, suggesting that the response is strongly dependent on other factors, but appeared to saturate (flatten) at higher PAR ${ }_{\text {amb }}$. These behaviours were reflected in $\mathrm{ECSt}_{\text {high-amb, }}$, which showed strong variability at lower $\mathrm{PAR}_{\mathrm{amb}}$ or $\mathrm{T}_{\text {leaf }}$, peaked at about 50-100 $\mu \mathrm{mol}$ photons $\mathrm{m}^{-2} \mathrm{~s}^{-1}$, and saturated at higher $\mathrm{PAR}_{\mathrm{amb}}$.

GMM analysis of ECSt ${ }_{\text {amb }}$ identified five distinct clusters (Fig. S11). The cluster at the lowest range of $\mathrm{PAR}_{\mathrm{amb}}$ (Cluster 1) showed dependence primarily on $\mathrm{PAR}_{\mathrm{amb}}$. The remaining clusters showed positive correlations between $\mathrm{ECSt}_{\mathrm{amb}}$ and $\mathrm{PAR}_{\mathrm{amb}}$, but negative correlations with $\mathrm{T}_{\text {leaf }}$. By contrast, GMM of $\mathrm{ECSt}_{\text {high }}$ (Fig. S12) showed almost no dependence on either PAR ${ }_{a m b}$ or $T_{\text {leaf }}$, except at the lowest PAR $_{a m b}$ (Cluster 1) which showed negative correlations with $\mathrm{PAR}_{\mathrm{amb}}$ and positive correlations with $\mathrm{T}_{\text {leaf }}$. 


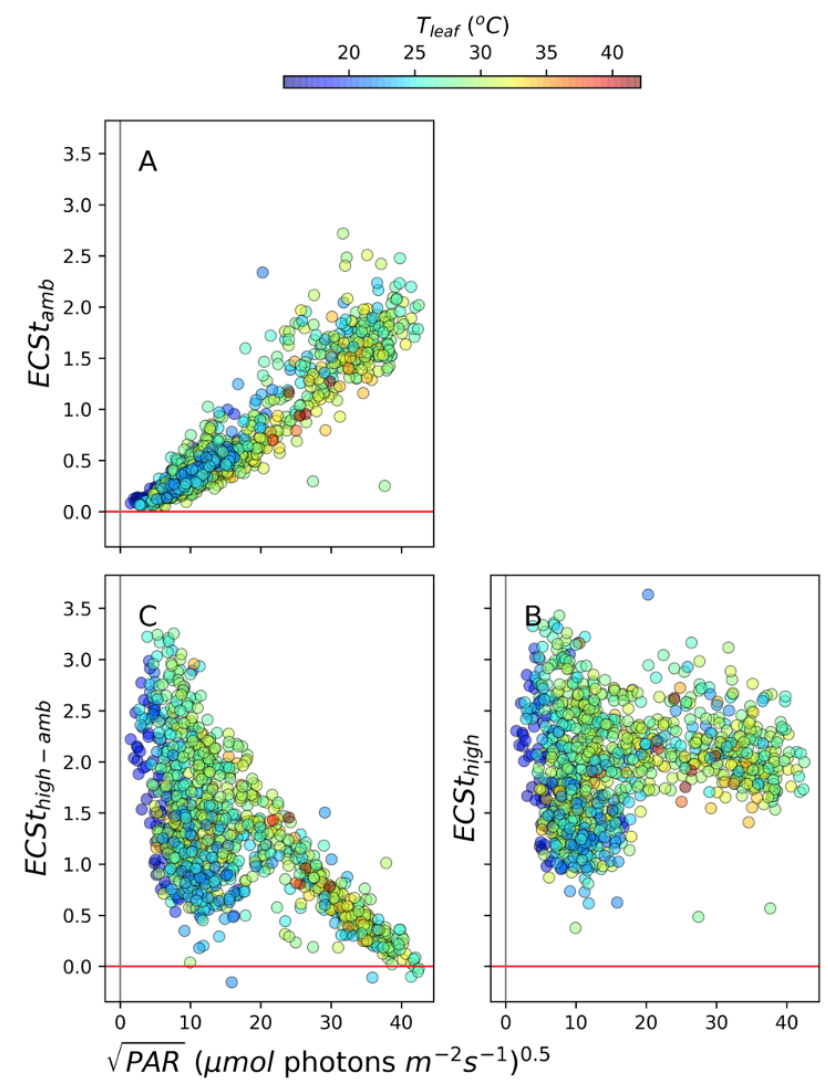

Figure 6. The light and temperature dependencies of the thylakoid pmf probed using ECSt signal. The pmf was measured using ECS under ambient light

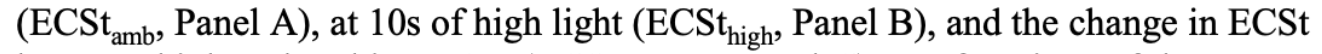

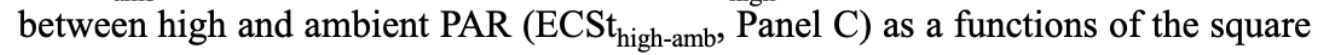
root of ambient PAR.

\section{Discussion}

\section{Using PhotosynQ and MultispeQ to sample and resolve the effects of environmental fluctuations on photosynthetic processes.}

The MultispeQ measurements described above were designed to explore the photosynthetic responses of plants in a natural, fluctuating environment. In this type of field experiment, it is not possible to control all variables. Rather, the strategy was to "sample" responses under as many conditions as practical, while recording key metadata so that subsequent analyses can assess the impacts of various environmental fluctuations. Thus the observed trends may 
reflect both primary and acclimatory factors that change (or accumulate) over different time scales. Correlations that appear in such analyses can be used to test, at least to some extent, certain models, though it is important to note that more controlled experiments will be needed to fully determine cause-effect relationships, as discussed below.

A major outcome of the experiment is that, despite the fact that measurements were made over many plants, times etc., clear patterns of responses emerged that allow us to make some broad conclusions about the responses of photosynthesis to ambient and rapidly changing light. For example, the majority of $\mathrm{NPQ}_{\text {high }}$ was found, in general, to be rapidly variable, suggesting that $\mathrm{qE}$ was the major contributor: At lower $\mathrm{PAR}_{\mathrm{amb}}$ that majority of $\mathrm{NPQ}_{\text {high }}$ was rapidly induced (see Fig. 3C), while at higher PARamb, pre-existing NPQ was rapidly recoverable (Fig. $3 \mathrm{E}$ ) at higher $\mathrm{PAR}_{\mathrm{amb}}$.

Another important trend was the suppression of the light potentials of both LEF (Fig. 2) and NPQ (Fig. 3) under some conditions, particularly under lower PAR $_{a m b}$ and/or $T_{\text {leaf. }}$ Further, strong decreases in $\mathrm{LEF}_{\text {high }}$ were not always accompanied by compensatory increases in $\mathrm{NPQ}_{\text {high }}$, implying that the productive and photoprotective light potentials can be simultaneously suppressed under certain conditions, a situation that is likely to promote the formation of reactive oxygen species and photodamage (see also below), with important implications for understanding the environmental robustness of photosynthesis [46].

\section{Disentangling interacting environmental impacts on photosynthetic processes.}

A key challenge to the field experiment approach is in teasing apart effects from different environmental factors, especially considering that such factors may be codependent or interact with each other in complex ways. For example, in visual inspection, most of parameters show apparent dependencies on both $\mathrm{PAR}_{\mathrm{amb}}$ and $\mathrm{T}_{\text {leaf }}$ (e.g. Figs. 2-6) but, because increases in $\mathrm{T}_{\text {leaf }}$ are often correlated with increases in $\mathrm{PAR}_{\mathrm{amb}}$, the effects of the two parameters may have been coincidental. It may also be that the environmental parameters interacted in complex ways, e.g. high $\mathrm{PAR}_{\mathrm{amb}}$ may have exacerbated the effects of low $\mathrm{T}_{\text {leaf. }}$ To address these issues, we applied an approach based on GMM to identify clusters representing distinct interactions among parameters. The approach is unsupervised, thus eliminating potential bias, while allowing us to test for changes in the environmental dependencies among multiple environmental parameters (Figs. S3-S12). 
Analysis of GMM clusters implied that most parameters were dependent on both PAR $_{\text {amb }}$ and $\mathrm{T}_{\text {leaf }}$, and at least under some conditions these effects are independent, or that one of the two factors predominates. Thus, the effects cannot be explained simply by coincidences between increased PAR and temperatures. Moreover, the non-rectilinear shapes of the clusters suggest that the effects of $\mathrm{PAR}_{\mathrm{amb}}$ and $\mathrm{T}_{\text {leaf }}$ were interactive, e.g., changes in $\mathrm{T}_{\text {leaf }}$ modulated the effects of $\mathrm{PAR}_{\mathrm{amb}}$ and vice versa. Overall, these interactions are in line with well-known temperature and PAR dependence of photosynthesis, but this type of analyses can reveal the specific combination of conditions that induce distinct behaviours, allowing for assessments of the involvement of specific mechanisms (see below) and to identify genotypic or management impacts on crop resilience and productivity.

At low PAR $_{\mathrm{amb}}$, we expect steady-state photosynthesis to be predominantly light-limited, and thus the effects of $\mathrm{T}_{\text {leaf }}$ should be low. As light increases, downstream biochemistry should become increasingly limiting. Because downstream energy storage and metabolic processes are likely to be more temperature dependent than photochemistry, this shift may allow us to distinguish between these types of limitations. Such behaviours are apparent in many of the measured parameters, e.g., $\mathrm{LEF}_{\mathrm{amb}}$, which was not substantially dependent on $\mathrm{T}_{\text {leaf }}$ at low PAR $\mathrm{Pamb}_{\mathrm{a}}$, but became codependent on $\mathrm{PAR}_{\mathrm{amb}}$ and $\mathrm{T}_{\text {leaf }}$ at higher $\mathrm{PAR}_{\mathrm{amb}}$ (Figs. 2A, $\mathrm{S} 3$ ), consistent with a progressive shift from light-limitation to assimilation-limitation.

Similarly, NPQ ${ }_{a m b}$ was solely dependent on $\mathrm{PAR}_{\mathrm{amb}}$ in the cluster at low $\mathrm{PAR}_{\mathrm{amb}}$, but became increasingly dependent on $\mathrm{T}_{\text {leaf }}$ as $\mathrm{PAR}_{\mathrm{amb}}$ increased (Fig. 3A). This shift is consistent with a control of $\mathrm{NPQ}_{\mathrm{amb}}$ by PAR (at low $\mathrm{PAR}_{\mathrm{amb}}$ ) and downstream metabolic processes, particularly at higher $\mathrm{PAR}_{\mathrm{amb}}$, e.g., due to regulation of the ATP synthase activity or cyclic electron flow (CEF) [47].

By contrast, $\mathrm{LEF}_{\text {high }}$ and $\mathrm{NPQ}_{\text {high }}$ showed much greater dependence on $\mathrm{T}_{\text {leaf }}$, and these differences were more pronounced when the high light was imposed on leaves at low $\mathrm{PAR}_{\mathrm{amb}}$ and $\mathrm{T}_{\text {leaf }}$, i.e. the opposite of what was seen for $\mathrm{LEF}_{\mathrm{amb}}$ and $\mathrm{NPQ}$ amb. Interestingly, the $\mathrm{LEF}_{\text {high }}$ rates achieved in leaves exposed to lower PAR $\mathrm{amb}_{\text {w }}$ were strongly suppressed

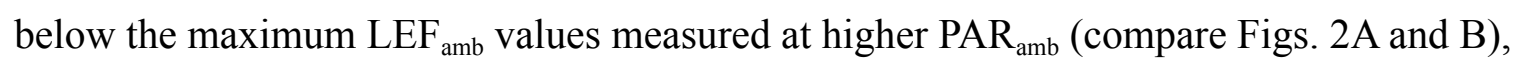
This behavior suggests that the suppression of $\mathrm{LEF}_{\text {high }}$ occurs when abrupt increases in light overwhelm the activation of downstream energy storage and metabolic processes. This is generally consistent with observations that the activities of metabolic enzymes are regulated 
to match the availability of energy from the light reactions, which involve large suite of co-regulatory processes, as extensively reviewed elsewhere, e.g. [16,47-53], but that these responses lag behind the changes in light. The in situ light potential measurements afforded by MultispeQ show that these situations are very likely to occur under many field situations.

These results also imply that accurate estimates of LEF, NPQ and other photosynthetic parameters will require measurements under ambient light, because sudden changes in PAR can lead to severe perturbations in photosynthetic limitations or regulation. Attempts to "simplify" field experiments by setting PAR to some constant value will lead to strong artifacts. Such effects are vividly demonstrated by the opposite dependencies of Phi $2_{\text {amb }}$ and Phi $2_{\text {high }}$ on PAR $_{\text {amb }}$ (Fig. 2D), and validate the use of the PAR matching feature of the MultispeQ instrument. It is important to keep in mind that the rates of acclimation may vary substantially between species, and that these may be assessed by performing more intensive experiments with variable high light and dark recovery times.

\section{Mechanisms for controlling the light potentials of LEF and NPQ using MultispeQ} field data.

The rapid reversal of $\mathrm{NPQ}_{\mathrm{amb}}$ and $\mathrm{NPQ}_{\text {high }}$ over $10 \mathrm{~s}$ of dark indicated that, under our conditions, NPQ is predominantly in the form of $\mathrm{qE}$ (Fig. 3B and $\mathrm{C}$ ), and thus dependent on lumen acidification and subsequent $\mathrm{pH}$-dependent responses. Lumen acidification can be controlled by changes in proton influx (through changes in LEF and CEF), proton efflux through the ATP synthase and the partitioning of pmf into electric field $(\Delta \psi)$ and $\Delta \mathrm{pH}$ components, which in turn, are impacted by metabolic status, as proposed earlier $[15,38]$. Here, we explore the possible mechanistic bases for these effects, by comparing the correlations among MultispeQ measurements.

Scheme 1 illustrates three basic mechanistic models describing proposed processes that can limit the light potentials of photosynthetic and photoprotective mechanisms. The models make qualitative predictions about how the actions of each mechanistic model will impact correlations between measured photosynthetic parameters, and thus can be used as a framework for interpreting the field data introduced in Results. The expected effects on the 
measured parameters are summarised in Scheme 1, which shows specific effects of each model.

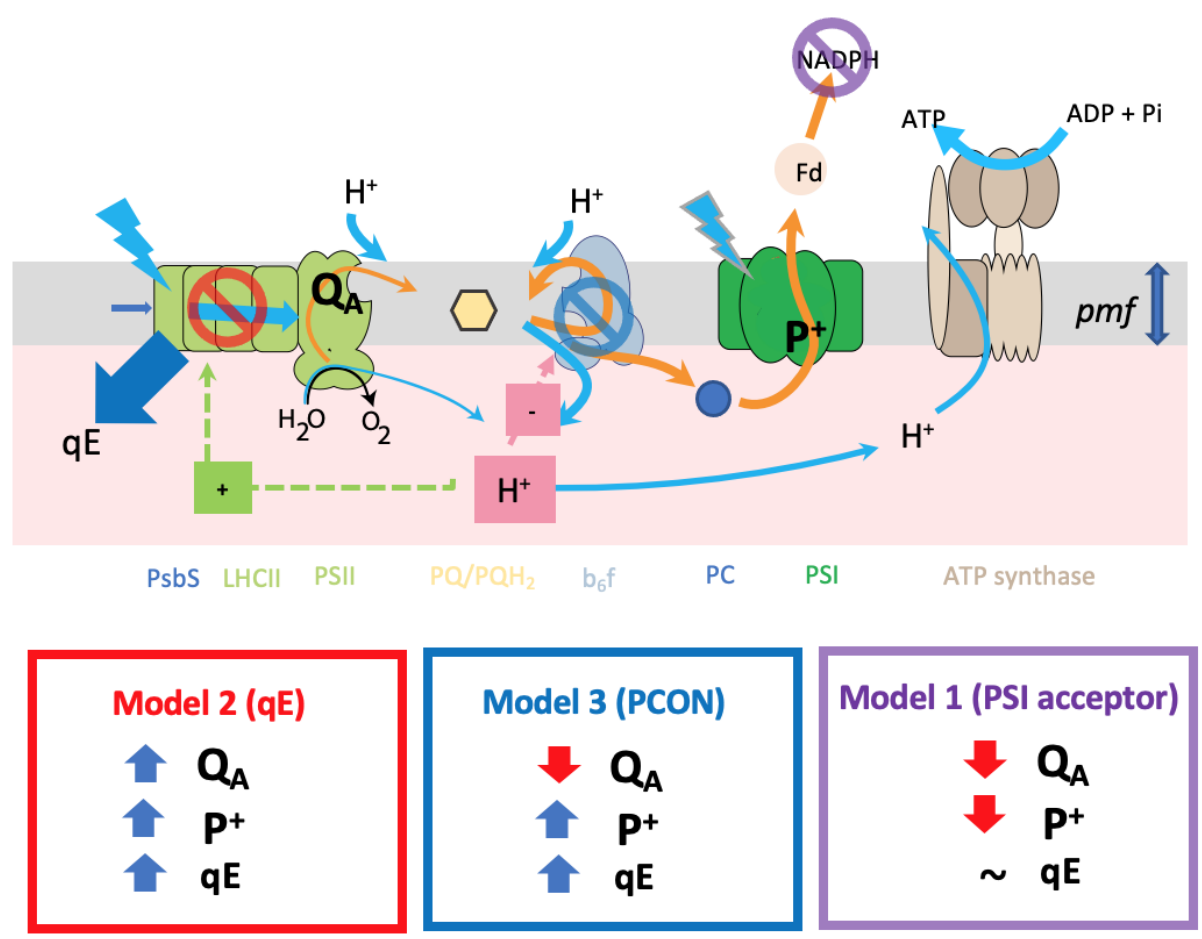

Scheme 1: Models for limitations to LEF and NPQ light potentials.

Model 1: PSI acceptor-side limitations (Scheme 1, Model 1) where lack of NADP ${ }^{+}$, ferredoxin or other PSI acceptors prevent further LEF. We expect this limitation to result in accumulation of electrons throughout the electron transfer chain, thus resulting in net reduction of $\mathrm{Q}_{\mathrm{A}}$ (decreasing $\mathrm{qL}$ ) and $\mathrm{P}_{700}{ }^{+}$(decreasing the $810 \mathrm{~nm}$ absorbance signal). The decreases in proton fluxes associated with backup of electrons may, in addition, prohibit rapid, light-induced increases in $p m f$, lumen acidification and $\mathrm{qE}$ responses.

Model 2: Increased NPQ (Scheme 1, Model 2). Increased NPQ should decrease delivery of excitation energy to PSII (but not to PSI), resulting in net oxidation of $\mathrm{Q}_{\mathrm{A}}$ (increasing $\mathrm{qL}$ ) and $\mathrm{P}_{700}{ }^{+}$(increased $810 \mathrm{~nm}$ DIRK signal). Under some conditions, the NPQ will be rapidly induced by increased $p m f$ and lumen acidification followed by activation of $\mathrm{qE}$, which should be visible as increased $\mathrm{NPQ}_{\text {high-amb. }}$ Under other conditions, e.g. at higher PAR $_{\mathrm{amb}}$, NPQ may already have been induced. If this NPQ is in the form of rapidly-reversible qE, it 
should substantially decay during the 10-s dark recovery period, resulting in increased $\mathrm{NPQ}_{\text {high-rec. }}$ More slowly-induced or relaxing forms of NPQ, including qI, qZ and long-lived $\mathrm{qE}$, may be also present prior to and throughout the experiment. The forms should register as increases in $\mathrm{NPQ}_{\text {rec }}$, but not in $\mathrm{NPQ}_{\text {high-amb }}$ or $\mathrm{NPQ}_{\text {high-rec}}$, but given that the high light and recovery periods were only 10 s long, our results do not allow us to distinguish among these possible forms.

Model 3: Photosynthetic control (PCON, Scheme 1, Model 3). PCON results from the slowing of $\mathrm{PQH}_{2}$ oxidation at the cytochrome $b_{6} f$ complex as the lumen becomes acidified. If $\mathrm{PCON}$ occurs without activation of $\mathrm{qE}$, we expect a net reduction of $\mathrm{Q}_{\mathrm{A}}$ (decreasing $\mathrm{qL}$ ) but a net oxidation of $\mathrm{P}^{+}$(increasing the $810 \mathrm{~nm}$ absorbance signal).

The qE and PCON models can be further subdivided [18,54]. In most cases, we expect lumen acidification accompanied by elevated $p m f$, reflected in an increased ECSt signal, which can be induced by increased proton influx into the lumen, due to increased LEF, increased CEF, or decreased conductivity of the thylakoid to protons $\left(g_{\mathrm{H}}{ }^{+}\right)$by slowing the ATP synthase. Alternatively, lumen acidification can also be associated with an increase in the fraction of $p m f$ that is stored as $\Delta \mathrm{pH}$, by controlling the flow of counterions across the thylakoid membrane, altering the partitioning of $p m f$ in $\Delta \mathrm{pH}$ and $\Delta \psi$. In this case, acidification may occur with little or no increases in total pmf, or the rates of proton influx, though the current field-based data do not allow us to directly distinguish these possibilities.

These models, while not mutually exclusive, will tend to counteract each other, at least within a particular leaf. For instance, PSI acceptor side limitations will tend to inhibit electron flow, thus decreasing proton flux and pmf generations. On the other hand, the generation of $p m f$ will tend to slow electron flow (through Models 2 or 3), thus preventing the buildup of electrons on PSI electron acceptors. However, it is important to note that, in a survey type experiment like ours, photosynthesis in different leaves may be limited by distinct processes, and thus any collection of samples may reflect various combinations of the above models.

\section{Testing models for limitations in light potentials.}


By plotting MultispeQ parameters against each other, we can test for more detailed patterns of behaviours predicted by the above models. Figure 7 shows that $\mathrm{P}^{+}$high-amb (high-light-induced $\mathrm{P}_{700}$ oxidation) was positively correlated with light-induced increases in $p m f\left(\mathrm{ECSt}_{\text {high-amb }}\right)$. Under all conditions, increasing PAR from $\mathrm{PAR}_{\mathrm{amb}}$ to $\mathrm{PAR}_{\text {high }}$ resulted in a net oxidation of $\mathrm{P}_{700}$, i.e., $\mathrm{P}^{+}$high-amb was consistently positive. This behaviour is consistent with Models 2 (NPQ) or 3 (PCON), both of which predict a decrease in delivery of electrons from PSII to PSI. By contrast, we did not see evidence for high light-induced net reduction of $\mathrm{P}_{700}{ }^{+}$, i.e., values of negative $\mathrm{P}^{+}$high-amb, implying that Model 1 was not a major limitation to light potential. This does not exclude Model 1 from limiting photosynthesis in different species and conditions, as has been proposed to be important in chilling sensitive plants [55]. However, the apparent avoidance of Model 1 (or prevalence of Models 2 and 3) behaviour may reflect the "tuning" of the light reactions to prevent the accumulation of reduced electron acceptors of PSI associated with photodamage [23], and the associated $\mathrm{O}_{2}$ caused by buildup of electrons on PSI [56].

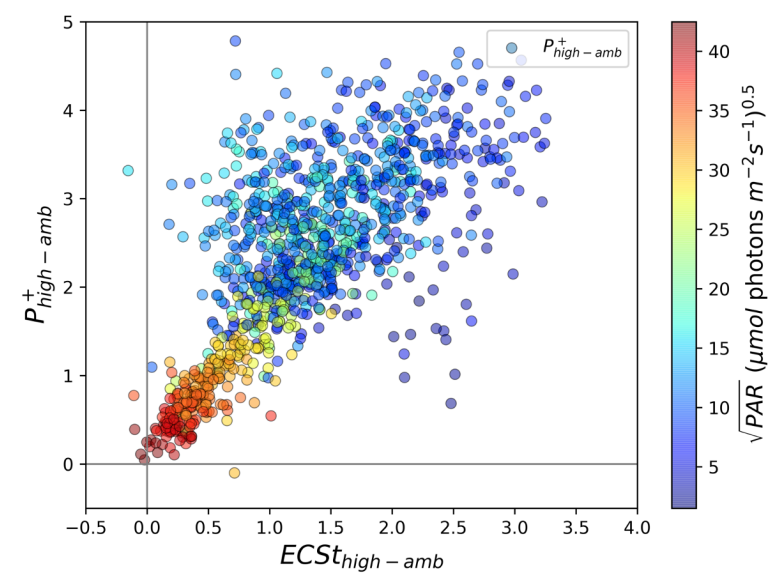

Figure 7. The relationship between light-induced thylakoid $p m f$ and changes in $\mathbf{P}_{\mathbf{7 0 0}}$ redox state. Changes in the thylakoid pmf $\left(\mathrm{ECSt}_{\text {high-amb }}\right)$ were estimated using the ECSt parameter, and changes in $\mathrm{P}_{700}{ }^{+}$were measured using the absorbance changes at $810 \mathrm{~nm}$, as described in Materials and Methods, under ambient light $\left(\mathrm{ECSt}_{\mathrm{amb}}, \mathrm{P}^{+}{ }_{\mathrm{amb}}\right)$ and after $10 \mathrm{~s}$ of high light $\left(\mathrm{ECSt}_{\text {high, }} \mathrm{P}^{+}{ }_{\mathrm{amb}}\right)$. The coloration of the points was set to a function of the square root of ambient PAR $\left(\mathrm{PAR}_{\mathrm{amb}}\right)$.

Overall, the behaviours seen in Fig. 7 are consistent with restrictions in electron flow to PSI imposed by increases in pmf, most likely through the acidification of the thylakoid lumen. In the case of Model 2 (rapid NPQ), this would be related to the induction of qE, while in Model 3 (PCON), this could be related to slowing of electron flow at the cytochrome $b_{6} f$ complex. 
Figure 8A further investigates this behaviour by plotting the dependence of high light-induced changes in $\mathrm{P}_{700}{ }^{+}\left(\mathrm{P}^{+}\right.$high-amb $)$with changes in $\mathrm{Q}_{\mathrm{A}}$ redox state $\left(\mathrm{qL}_{\text {high-amb }}\right)$. The expected theoretical behaviours for the three models are indicated by the coloured boxes in the figure, and can be related to Models 1-3 in Scheme 1:

- Model 1 (violet box) predicts net reduction of $\mathrm{P}_{700}\left(\mathrm{P}_{\text {high-amb }}^{+}<0\right)$ and net reduction $\mathrm{Q}_{\mathrm{A}}(\mathrm{qL}$ high-amb $<0)$

- Model 2 (red box) predicts net oxidation of $\mathrm{P}_{700}\left(\mathrm{P}_{\text {high-amb }}^{+}>0\right)$ and net oxidation $\mathrm{Q}_{\mathrm{A}}$ $\left(\mathrm{qL}_{\text {high-amb }}>0\right)$

- Model 3 (blue box) predicts net oxidation of $\mathrm{P}_{700}\left(\mathrm{P}^{+}{ }_{\text {high-amb }}>0\right)$ but net reduction $\mathrm{Q}_{\mathrm{A}}(\mathrm{qL}$ high-amb $<0)$

We observe behaviours consistent with both Models 2 and 3, suggesting that the behaviour of the system changed with conditions. Note that the boxes in Figure 8A represent "pure" behaviours, and it is possible that the effects of a particular mechanism may be intermediate, e.g., the responses may be limited by a combination of reduction of $\mathrm{Q}_{\mathrm{A}}$ and increased NPQ.
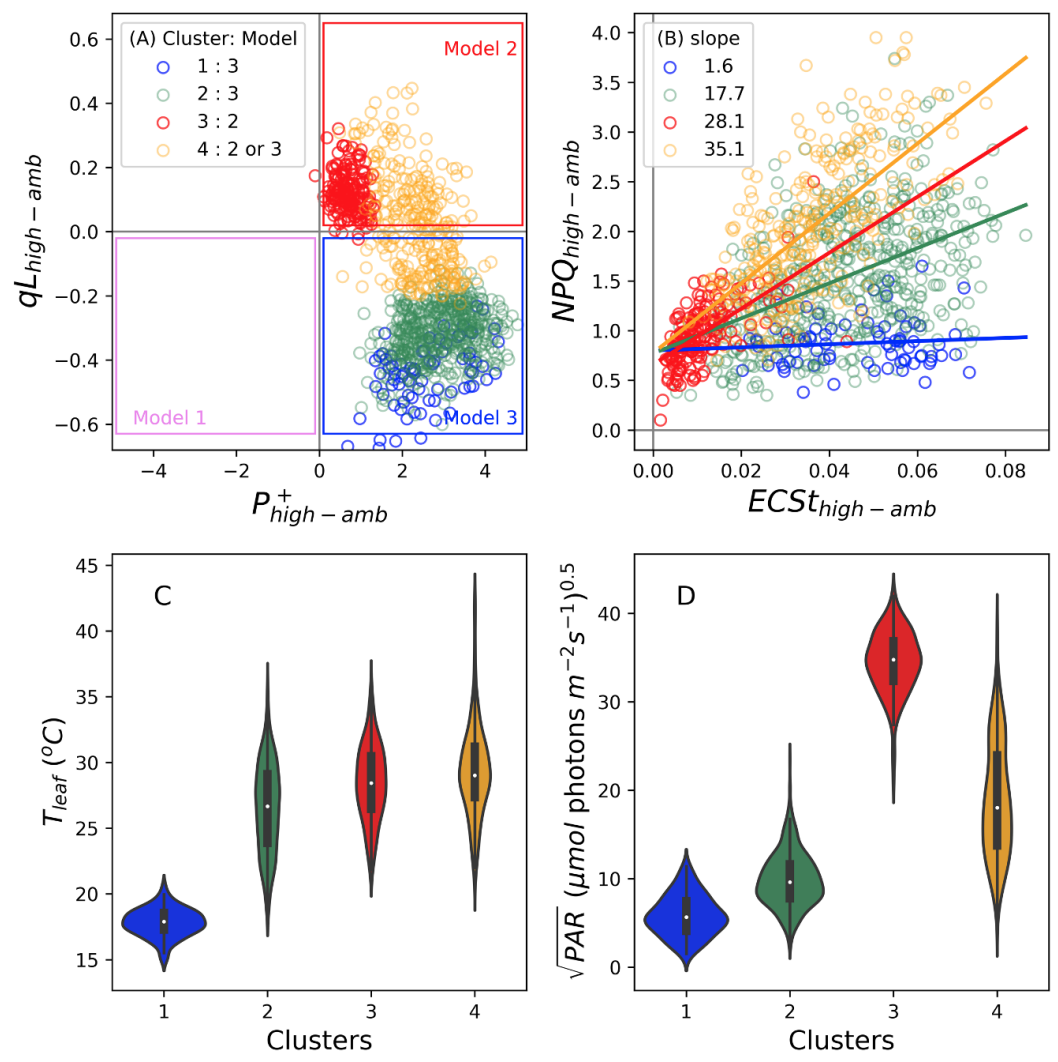
Figure 8. The relationships between light-induced changes in $Q_{A}$ redox state and $P_{700}$ redox state (Panel $A$ ), and between rapidly inducible NPQ and thylakoid pmf (Panel B) and the leaf temperature (Panel C) and PAR (Panel D) dependencies of Gaussian Mixture Models (GMM) clusters. Changes in $\mathrm{P}_{700}{ }^{+}$ $\left(\mathrm{P}_{\text {high-amb), }}^{+} \mathrm{Q}_{\mathrm{A}}\right.$ redox state $\left(\mathrm{qL}_{\text {high-amb }}\right)$, rapid changes in $\mathrm{NPQ}\left(\mathrm{NPQ} \mathrm{h}_{\text {high-amb }}\right)$ and thylakpoid $p m f\left(E_{\text {CSt }}\right.$ high-amb $)$ were measured as described in Materials and Methods. Data were clustered using the GMM approach described in the text, resulting in four distinct clusters, designated buy the blue, green, red and ocher symbol colors (see legend in Panel A). In Panel B, the slopes for the relationship between $\mathrm{NPQ}_{\text {high-amb }}$ and $\mathrm{ECSt}_{\text {high-amb }}$ were estimated by linear regression (slopes for clusters 1,2,3 and 4 were estimated to be 1.6, 17.7, 28.1 and 35.1, respectively). Panels C and D show distributions of leaf temperatures $\left(\mathrm{T}_{\text {leaf, }}\right.$ Panel $\mathrm{C}$ ) and square root of ambient PAR for each cluster in Panels A and B.

Figure $8 \mathrm{~B}$ plots the dependence of $\mathrm{NPQ}_{\text {high-amb}}$, which can be attributed to light-induced $\mathrm{qE}$ changes, on light-induced pmf changes $\left(\mathrm{ECSt}_{\text {high-amb }}\right)$. A generally positive correlation was observed between $\mathrm{NPQ}_{\text {high-amb }}$ and $\mathrm{ECSt}_{\text {high-amb}}$, but with high variability, especially at higher values. Applying the clustering obtained for Fig. 8A on top of the data in Fig. 8B, we see that this variability can be explained by the environmental conditions and the modes of behaviours. Specifically, we see clear evidence for condition-dependent suppression of rapid activation of $\mathrm{qE}$ in response to increases in $p m f$. Particularly, the sensitivities of $\mathrm{NPQ}_{\text {high-amb }}$ to $\mathrm{ECSt}_{\text {high-amb}}$, as indicated by the slopes in Fig. 8B, were smallest in Clusters 1 (slope $\sim 1.6$ ) and 2 (slope $~ 17.7$ ), which comprise those with Model 3-like behaviour and occured at low $\mathrm{T}_{\text {leaf }}$ and $\mathrm{PAR}_{\text {amb }}$ values. Higher sensitivities of $\mathrm{NPQ}_{\text {high-amb }}$ to $\mathrm{ECSt}_{\text {high-amb }}$ were seen for Clusters 3 (slope $\sim 28.1$ ) and 4 (slope $\sim 35.1$ ), which comprised those associated with Models 2 and intermediate, and occurred at higher $\mathrm{T}_{\text {leaf }}$ and $\mathrm{PAR}_{\mathrm{amb}}$ values.

To assess what controlled the switch between Models 2 and 3, we performed GMM (using $\mathrm{qL}_{\text {high-amb }}, \mathrm{P}^{+}{ }_{\text {high-amb}}, \mathrm{T}_{\text {leaf }}$ as inputs). Four distinct clusters were observed (see symbol colours, Fig. 8A). Intercluster comparisons show that points in Clusters 1 and 2 fell exclusively in the region predicted for Model 3. Cluster 3 fell entirely within the region predicted for Model 2. Cluster 4 extended between these regions, possibly indicating contributions from both mechanisms. The clusters falling in the Model 3 region were associated with relatively low $\mathrm{T}_{\text {leaf }}$ (Fig. 8C) and PAR $_{\text {amb }}$ (Fig. 8D), compared to those associated with Model 2 or intermediate behaviours, suggesting that Model 2 prevailed at higher $\mathrm{T}_{\text {leaf }}$ and/or $\mathrm{PAR}_{\mathrm{amb}}$, while Model 3 prevailed at lower values. Within the GMM clusters (Fig. S13), qL $L_{\text {high-amb }}$ was dependent predominantly on $\mathrm{T}_{\text {leaf }}$ (Cluster 3), $\mathrm{PAR}_{\mathrm{amb}}$ (Cluster 1), or both (Clusters 2 and 4). This dependence suggests that $T_{\text {leaf }}$ and $\mathrm{PAR}_{\mathrm{amb}}$ acted either independently or 
cooperatively, depending on conditions, affecting the propensity for photosynthesis to adopt Model 2 or 3 behaviours.

The data in Figs. 8 show that, at lower $\mathrm{T}_{\text {leaf }}$ and $\mathrm{PAR}_{\mathrm{amb}}$, $\mathrm{qE}$ activation was suppressed despite light-induced increases in $p m f$, and that this behaviour was associated with accumulation of electrons on $\mathrm{Q}_{\mathrm{A}}$ but oxidation of $\mathrm{P}_{700}$ (Fig. 8A), suggesting that, under these conditions, light-induced increases in $\Delta \mathrm{pH}$ caused slowing of the cytochrome $b_{6} f$ complex (PCON), but that the $\mathrm{qE}$ response lagged behind or was completely suppressed, leading to Model 3 behaviour.

It has been shown that the lumen $\mathrm{pH}$-dependencies of $\mathrm{qE}$ and $\mathrm{PQH}_{2}$ oxidation by the cytochrome $b_{6} f$ complex are tightly coordinated, so that increased lumen acidity activates photoprotection prior to PCON, presumably to prevent the accumulation of reduced $\mathrm{Q}_{\mathrm{A}}$ [54]. However, these experiments were performed under more slowly-changing (near steady-state) conditions in the laboratory, and our results suggest that this coordination can be defeated under real world conditions in the field, especially when $T_{\text {leaf }}$ is low and PAR fluctuates rapidly. This discoordination can have strong implications for photodamage, as it has been shown that high thylakoid pmf can greatly accelerate PSII recombination reactions, especially when $\mathrm{Q}_{\mathrm{A}}$ is reduced, leading to ${ }^{1} \mathrm{O}_{2}$ production $[28,29]$. It thus seems reasonable to suggest that the shift from $\mathrm{qE}$ to PCON at low $\mathrm{T}_{\text {leaf }}$ will increase the rates of photodamage.

There are several possible mechanisms by which the response of $\mathrm{qE}$ can be uncoupled from increased $p m f$. Longer-term dependencies of NPQ on temperature have been reported under both field [57-59] and laboratory [60][61] conditions. The current work shows effects on rapid NPQ and LEF changes, which can be related to distinct mechanistic models. For example, it is known that the xanthophyll cycle is strongly temperature dependent, though the general observation is that zeaxanthin tends to accumulate at lower temperatures due to a slowing of the epoxidation of zeaxanthin $[60][61,62]$. Interestingly, we would expect the accumulation of zeaxanthin to augment, rather than suppress $\mathrm{qE}$ responses as we have observed in the current results. Lumen acidification may also be rate limiting for formation of qE. While rapid increase in light can result in nearly instantaneous increases in $\Delta \psi$, formation of $\Delta \mathrm{pH}$ and lumen acidification requires counterion transport processes, which tend to be slow, and thus lumen acidification lags behind [25,29], and it is possible that this 
process is substantially slowed at low temperature. Other possible limitations include temperature-dependence of conformational rearrangement of antenna complexes following protonation of PsbS $[63,64]$, which in turn may be related to the interactions among thylakoid proteins, lipids and ultrastructure $[12,44,65,66]$. The current data does not allow us to discriminate between these models with the current data set, but the work suggests conditions and species under which such limitations occur, and how they may impact plant productivity or resilience.

\section{Conclusion: Current limitations and prospects for open science-led efforts to understand and improve photosynthesis.}

There are intense, ongoing efforts to improve photosynthesis, yet the importance of the responses of photosynthesis under fluctuating, real world conditions are just now being recognised. In particular, we lack understanding of the extents and impacts of these responses, as well as their mechanisms and genomic control, which will be critical to achieving field-relevant improvements in efficiency and robustness, especially in a changing environment.

Here, we demonstrate methods and tools to assess the light responses of photosynthetic processes under real world conditions, and use them to explore the factors that limit the capacity of plants to utilise or dissipate rapidly increased PAR. A major outcome is that, despite the complexities of field environments, clear behavioural patterns can be resolved, as long as the experiment contains a sufficient number of points taken over a large environmental space, and that includes both environmental metadata. Such combinations of information allow for the generation and testing of specific hypotheses. For example, we observed no evidence for Model 1 behaviour in the current study, but we do not exclude the possibility in different species and/or different environmental conditions. The rapid measurements allowed us to test for various models over broad-scales by looking for internally-consistent relationships among the various measured parameters. Further, while we surmised (above) that Model 3 type behaviour would likely lead to photodamage, we do not have independent endpoint measurements (e.g., yield, growth rates etc.) to validate that the propensity for Model 3 behaviour has long-term consequences. The models are not exclusive, and there will almost certainly be cases, e.g., Cluster 4 in Fig. 8, where 
intermediate behaviours will be apparent, either because of co-limitations among multiple processes or heterogeneity between chloroplasts in the leaf samples.

We also emphasise that the data presented here was intended to introduce the approaches and methods, and thus leaves a number of questions unanswered, but sets up the approach to further study. The origins of these effects may include several classes of processes $[31,67]$, that may differ under different conditions [68], including induction of downstream assimilatory reactions and metabolic pools [69,70], downstream sink reactions [71], redox regulation [72,73], balancing between the production and consumption of ATP and NADPH $[1,49]$, ion homeostasis and regulation of thylakoid $\operatorname{pmf}[25,74]$, low stomatal aperture that may lead to transient depletion of internal $\mathrm{CO}_{2}$ levels . Distinguishing these will likely require more detailed phenotyping and biochemical [10,56,75], modeling [31] and genomics and genetics approaches [76].

The accessibility of the tools should allow larger numbers of researchers to answer these types of questions over a broader set of results, as will be presented in an upcoming paper. This approach was made possible by the combination of several open science advances. Collation of large amounts of data and metadata through the MultispeQ and PhotosynQ platforms [33], allowing us to explore the interdependencies of multiple phenotypes and environmental conditions (metadata). The GMM methods allowed us to explore the interactions among multiple environmental parameters and photosynthetic phenotypes, and test for the participation of distinct mechanistic models to explain the limitations to photosynthesis under field conditions, leading to the identification of distinct limitations in the rapid activation of NPQ and LEF at low temperature. Finally, making all tools, protocols and analytical methods available in directly usable forms, the project can be readily expanded to include multiple environments and species, as well as alternative models.

Acknowledgements. The authors thank Dr. Ute Armbruster, Thekla von Bismarck, Dr. Nicholas Fisher, Dr. Jennifer Johnson, Dr. Thomas Avenson and Oliver Tessmer for valuable discussions and critical reading of the manuscript and for numerous contributors to PhotosynQ data sets. 
Funding. Development of the protocols and data analysis methods was supported by the U.S. Department of Energy (DOE), Office of Science, Basic Energy Sciences (BES) under Award number DE-FG02-91ER20021. The setup and collection of field data by A.K. and H.T. was funded by the U.S. National Science Foundation (1847193). D.M.K. received partial salary support from Michigan AgBioResearch.

Data accessibility. Primary data is available on the photosynq.org site under the project “rapid-ps-responses-pam-ecst-npqt-mint-dmk". Data cleaning and analysis code is available in a GitHub repository (https://github.com/protonzilla/Light-Potentials-in-Field).

Competing interests. D.M.K. and S.K. are co-founders of PhotosynQ which maintains the PhotosynQ platforms and distributes and maintains the MultispeQ instruments. The current project was performed independently with no funding to or from the PhotosynQ organization.

Author contributions. A.K. and D.M.K. designed the experiments. A.K. and H.T. conducted experiments. A.K., A.C., S.K. and D.M.K. analyzed data. A.K., A.C., S.K., T.M. and D.M.K. contributed to the interpretations of data and writing manuscript.

\section{References}

1. Kramer DM, Evans JR. 2011 The importance of energy balance in improving photosynthetic productivity. Plant Physiol. 155, 70-78.

2. Li XP, Gilmore AM, Caffarri S, Bassi R, Golan T, Kramer D, Niyogi KK. 2004 Regulation of photosynthetic light harvesting involves intrathylakoid lumen $\mathrm{pH}$ sensing by the PsbS protein. J. Biol. Chem. 279, 22866-22874.

3. Kromdijk J, Glowacka K, Leonelli L, Gabilly ST, Iwai M, Niyogi KK, Long SP. 2016 Improving photosynthesis and crop productivity by accelerating recovery from photoprotection. Science 354, 857-861.

4. Li XP, Muller-Moule P, Gilmore AM, Niyogi KK. 2002 PsbS-dependent enhancement of feedback de-excitation protects photosystem II from photoinhibition. Proc. Natl. Acad. Sci. U. S. A. 99, 15222-15227.

5. Eskling M, Arvidsson P-O, Akerlund H-E. 1997 The xanthophyll cycle, its regulation and components. Physiol. Plant. 100, 806-816.

6. Demmig-Adams B. 1990 Carotenoids and photoprotection in plants: A role for the xanthophyll zeaxanthin. Biochim. Biophys. Acta 1020, 1-24.

7. Niyogi KK, Björkman O, Grossman AR. 1997 The roles of specific xanthophylls in 
photoprotection. Proc. Natl. Acad. Sci. U. S. A. 94, 14162-14167.

8. Eskling M, Emanuelsson A, Akerlund H-E. 2001 Enzymes and mechanisms for violaxanthin-zeaxanthin conversion. In Regulation of Photosynthesis (eds E-M Aro, B Anderson), pp. 806-816. Dordrecht, The Netherlands: Kluwer Academic Publishers.

9. Kunz HH, Gierth M, Herdean A, Satoh-Cruz M, Kramer DM, Spetea C, Schroeder JI. 2014 Plastidial transporters KEA1, -2, and -3 are essential for chloroplast osmoregulation, integrity, and $\mathrm{pH}$ regulation in Arabidopsis. Proc. Natl. Acad. Sci. U. S. A. 111, 7480-7485.

10. Armbruster U et al. 2014 Ion antiport accelerates photosynthetic acclimation in fluctuating light environments. Nat. Commun. 5, 5439.

11. Davis GA, William Rutherford A, Kramer DM. 2017 Hacking the thylakoid proton motive force (pmf) for improved photosynthesis: Possibilities and pitfalls. Philos. Trans. R. Soc. Lond. B Biol. Sci. 372, 20160381.

12. Jahns P, Holzwarth AR. 2012 The role of the xanthophyll cycle and of lutein in photoprotection of photosystem II. Biochim. Biophys. Acta 1817, 182-193.

13. Malnoë A, Schultink A, Shahrasbi S, Rumeau D, Havaux M, Niyogi KK. 2018 The Plastid Lipocalin LCNP Is Required for Sustained Photoprotective Energy Dissipation in Arabidopsis. Plant Cell 30, 196-208.

14. Schiphorst C, Bassi R. 2020 Chlorophyll-Xanthophyll Antenna Complexes: In Between Light Harvesting and Energy Dissipation. In Photosynthesis in Algae: Biochemical and Physiological Mechanisms (eds AWD Larkum, AR Grossman, JA Raven), pp. 27-55. Cham: Springer International Publishing.

15. Takizawa K, Kanazawa A, Cruz JA, Kramer DM. 2007 In vivo thylakoid proton motive force. Quantitative non-invasive probes show the relative lumen $\mathrm{pH}$-induced regulatory responses of antenna and electron transfer. Biochim. Biophys. Acta 1767, 1233-1244.

16. Avenson TJ, Kanazawa A, Cruz JA, Takizawa K, Ettinger WE, Kramer DM. 2005 Integrating the proton circuit into photosynthesis: Progress and challenges. Plant Cell Environ. 28, 97-109.

17. Vershubskii AV, Tikhonov AN. 2020 pH-Dependent Regulation of Electron and Proton Transport in Chloroplasts In Situ and In Silico. Biochemistry (Moscow), Supplement Series A: Membrane and Cell Biology 14, 154-165.

18. Kanazawa A, Neofotis P, Davis GA, Fisher N, Kramer DM. 2020 Diversity in Photoprotection and Energy Balancing in Terrestrial and Aquatic Phototrophs. In Photosynthesis in Algae: Biochemical and Physiological Mechanisms (eds AWD Larkum, AR Grossman, JA Raven), pp. 299-327. Cham: Springer International Publishing.

19. Takahashi S, Milward SE, Fan DY, Chow WS, Badger MR. 2009 How does cyclic electron flow alleviate photoinhibition in Arabidopsis? Plant Physiol. 149, 1560-1567.

20. Chow WS, Hope AB. 1977 Proton Translocation, Electron Transport and Photophosphorylation in Isolated Chloroplasts. Plant Physiol. 4, 647-665.

21. Allahverdiyeva Y, Suorsa M, Tikkanen M, Aro EM. 2015 Photoprotection of photosystems in fluctuating light intensities. J. Exp. Bot. 66, 2427-2436.

22. Suorsa M et al. 2012 PROTON GRADIENT REGULATION5 Is Essential for Proper Acclimation of Arabidopsis Photosystem I to Naturally and Artificially Fluctuating Light Conditions. Plant Cell 24, 2934-2948. 
23. Kanazawa A et al. 2017 Chloroplast ATP synthase modulation of the thylakoid proton motive force: Implications for photosystem I and photosystem II photoprotection. Frontiers in Plant Physiology https://doi.org/10.3389/fpls.2017.00719.

24. Chaux F, Burlacot A, Mekhalfi M, Auroy P, Blangy S, Richaud P, Peltier G. 2017 Flavodiiron Proteins Promote Fast and Transient O2 Photoreduction in Chlamydomonas. Plant Physiol. 174, 1825-1836.

25. Armbruster U, Leonelli L, Correa Galvis V, Strand D, Quinn EH, Jonikas MC, Niyogi KK. 2016 Regulation and Levels of the Thylakoid K+/H+ Antiporter KEA3 Shape the Dynamic Response of Photosynthesis in Fluctuating Light. Plant Cell Physiol. (doi:10.1093/pcp/pcw085)

26. Kulheim C, Agren J, Jansson S. 2002 Rapid regulation of light harvesting and plant fitness in the field. Science 297, 91-93.

27. Allahverdiyeva Y, Mustila H, Ermakova M, Bersanini L, Richaud P, Ajlani G, Battchikova N, Cournac L, Aro EM. 2013 Flavodiiron proteins Flv1 and Flv3 enable cyanobacterial growth and photosynthesis under fluctuating light. Proc. Natl. Acad. Sci. U. S. A. 110, 4111-4116.

28. Cruz JA, Savage LJ, Zegarac R, Hall CC, Satoh-Cruz M, Davis GA, Kovac WK, Chen J, Kramer DM. 2016 Dynamic environmental photosynthetic imaging reveals emergent phenotypes. Cell Syst 2, 365-377.

29. Davis GA et al. 2016 Limitations to photosynthesis by proton motive force-induced photosystem II photodamage. Elife eLife 2016;5:e16921.

30. Murchie EH, Niyogi KK. 2011 Manipulation of photoprotection to improve plant photosynthesis. Plant Physiol. 155, 86-92.

31. Gjindali A, Herrmann HA, Schwartz J-M, Johnson GN, Calzadilla PI. 2021 A Holistic Approach to Study Photosynthetic Acclimation Responses of Plants to Fluctuating Light. Front. Plant Sci. 12, 668512.

32. Zhu XG, Long SP, Ort DR. 2010 Improving photosynthetic efficiency for greater yield. Annu. Rev. Plant Biol. 61, 235-261.

33. Kuhlgert $\mathrm{S}$ et al. 2016 MultispeQ Beta: a tool for large-scale plant phenotyping connected to the open PhotosynQ network. R Soc Open Sci 3, 160592.

34. Loriaux SD, Avenson TJ, Welles JM, McDermitt DK, Eckles RD, Riensche B, Genty B. 2013 Closing in on maximum yield of chlorophyll fluorescence using a single multiphase flash of sub-saturating intensity. Plant Cell Environ. 2013/04/17. (doi:10.1111/pce.12115)

35. Genty B, Briantais J-M, Baker NR. 1989 The relationship between the quantum yield of photosynthetic electron transport and quenching of chlorophyll fluorescence. Biochim. Biophys. Acta 990, 87-92.

36. Kramer DM, Johnson G, Kiirats O, Edwards GE. 2004 New fluorescence parameters for the determination of $\mathrm{Q}_{\mathrm{A}}$ redox state and excitation energy fluxes. Photosynth. Res. 79, 209-218.

37. Tietz S, Hall CC, Cruz JA, Kramer DM. 2017 NPQ(T): a chlorophyll fluorescence parameter for rapid estimation and imaging of non-photochemical quenching of excitons in photosystem II associated antenna complexes. Plant Cell Environ. 40, 1243-1255.

38. Kanazawa A, Kramer DM. 2002 In vivo modulation of nonphotochemical exciton quenching (NPQ) by regulation of the chloroplast ATP synthase. Proc. Natl. Acad. Sci. U. S. A. 99, 
$12789-12794$.

39. Baker N, Harbinson J, Kramer DM. 2007 Determining the limitations and regulation of photosynthetic energy transduction in leaves. Plant Cell Environ. 30, 1107-1125.

40. Scrucca L, Fop M, Murphy TB, Raftery AE. 2016 mclust 5: clustering, classification and density estimation using Gaussian finite mixture models. $R J$.

41. Fraley C, Raftery AE. 2002 Model-Based Clustering, Discriminant Analysis, and Density Estimation. J. Am. Stat. Assoc. 97, 611-631.

42. Dasgupta A, Raftery AE. 1998 Detecting Features in Spatial Point Processes with Clutter via Model-Based Clustering. J. Am. Stat. Assoc. 93, 294-302.

43. Fraley C, Raftery AE. 1998 How Many Clusters? Which Clustering Method? Answers Via Model-Based Cluster Analysis. Comput. J. 41, 578-588.

44. Lambrev PH, Miloslavina Y, Jahns P, Holzwarth AR. 2012 On the relationship between non-photochemical quenching and photoprotection of Photosystem II. Biochim. Biophys. Acta 1817, 760-769.

45. Holzwarth AR, Miloslavina Y, Nilkens M, Jahns P. 2009 Identification of two quenching sites active in the regulation of photosynthetic light-harvesting studied by time-resolved fluorescence. Chem. Phys. Lett. 483, 262-267.

46. Davis GA et al. 2016 Limitations to photosynthesis by proton motive force-induced photosystem II photodamage. Elife 5. (doi:10.7554/eLife.16921)

47. Strand DD, Kramer •. D. M. 2014 Control of non-photochemical exciton quenching by the proton circuit of photosynthesis. In Non-Photochemical Quenching and Energy Dissipation in Plants, Algae and Cyanobacteria (eds B Demmig-Adams, G Garab, W Adams III, Govindjee), pp. 387-408. The Netherlands: Springer.

48. Foyer C, Furbank R, Harbinson J, Horton P. 1990 The mechanisms contributing to photosynthetic control of electron transport by carbon assimilation in leaves. Photosynth. Res. 25, 83-100.

49. Noctor G, Foyer CH. 2000 Homeostasis of adenylate status during photosynthesis in a fluctuating environment. J. Exp. Bot. 51, 347-356.

50. Stitt M. 1996 Metabolic regulation of photosynthesis. In Photosynthesis and the Environment (ed NR Baker), pp. 151-190. Dordrecht: Kluwer Academic Publishers.

51. Preiser AL, Fisher N, Banerjee A, Sharkey TD. 2019 Plastidic glucose-6-phosphate dehydrogenases are regulated to maintain activity in the light. Biochem. J 476, 1539-1551.

52. Cejudo FJ, Ojeda V, Delgado-Requerey V, González M, Pérez-Ruiz JM. 2019 Chloroplast Redox Regulatory Mechanisms in Plant Adaptation to Light and Darkness. Front. Plant Sci. 10, 380 .

53. Hochmal AK, Schulze S, Trompelt K, Hippler M. 2015 Calcium-dependent regulation of photosynthesis. Biochim. Biophys. Acta 1847, 993-1003.

54. Takizawa K, Cruz JA, Kanazawa A, Kramer DM. 2007 The thylakoid proton motive force in vivo. Quantitative, non-invasive probes, energetics, and regulatory consequences of light-induced pmf. Biochim. Biophys. Acta 1767, 1233-1244. 
55. Sonoike K, Terashima I. 1994 Mechanism of photosystem-I photoinhibition in leaves of Cucumis sativus L. Planta 194, 287-293.

56. Huang W, Sun H, Tan S-L, Zhang S-B. 2021 The water-water cycle is not a major alternative sink in fluctuating light at chilling temperature. Plant Sci. 305, 110828.

57. Lambrev PH, Tsonev T, Velikova V, Georgieva K, Lambreva MD, Yordanov I, Kovács L, Garab G. 2007 Trapping of the quenched conformation associated with non-photochemical quenching of chlorophyll fluorescence at low temperature. Photosynth. Res. 94, 321-332.

58. Demmig B. 1987 Photoinhibition and zeaxanthin formation in intact leaves. Plant Physiol. 84, $218-224$.

59. Greer DH, Berry JA, Björkman O. 1986 Photoinhibition of photosynthesis in intact bean leaves: role of light and temperature, and requirement for chloroplast-protein synthesis during recovery. Planta 168, 253-260.

60. Bilger W, Björkman O. 1991 Temperature dependence of violaxanthin de-epoxidation and non-photochemical fluorescence quenching in intact leaves of Gossypium hirsutum L. and Malva parviflora L. Planta 184, 226-234.

61. Adams WW, Demmig-Adams B. 1995 The xanthophyll cycle and sustained thermal energy dissipation activity in Vinca minor and Euonymus kiautschovicus in winter. Plant, Cell and Environment. 18, 117-127. (doi:10.1111/j.1365-3040.1995.tb00345.x)

62. Verhoeven AS, Adams WW III, Demmig-Adams B. 1996 Close relationship between the state of the xanthophyll cycle pigments and photosystem II efficiency during recovery from winter stress. Physiologia Plantarum. 96, 567-576. (doi:10.1034/j.1399-3054.1996.960404.x)

63. Mullineaux CW, Pascal AA, Horton P, Holzwarth AR. 1993 Excitation-energy quenching in aggregates of the LHCII Chlorophyll-protein complex - a time-resolved fluorescence study. Biochim. Biophys. Acta 1141, 23-28.

64. Rees S, Young A, Noctor G, Horton P. 1989 Enhancement of the DpH-dependent dissipation of excitation energy in spinach chloroplasts by light-activation: correlation with the synthesis of zeaxanthin. FEBS Lett. 256, 85-90.

65. Horton P, Wentworth M, Ruban A. 2005 Control of the light harvesting function of chloroplast membranes: the LHCII-aggregation model for non-photochemical quenching. FEBS Lett. 579, 4201-4206.

66. Kirchhoff H, Hall C, Wood M, Herbstova M, Tsabari O, Nevo R, Charuvi D, Shimoni E, Reich Z. 2011 Dynamic control of protein diffusion within the granal thylakoid lumen. Proc. Natl. Acad. Sci. U. S. A. 108, 20248-20253.

67. Kaiser E, Morales A, Harbinson J. 2018 Fluctuating Light Takes Crop Photosynthesis on a Rollercoaster Ride. Plant Physiol. 176, 977-989.

68. Anderson CM et al. 2021 High Light and High Temperature Reduce Photosynthesis via Different Mechanisms in the C4 Model Setaria viridis. bioRxiv. , 2021.02.20.431694. (doi:10.1101/2021.02.20.431694)

69. Stitt M, Zhu X-G. 2014 The large pools of metabolites involved in intercellular metabolite shuttles in $\mathrm{C} 4$ photosynthesis provide enormous flexibility and robustness in a fluctuating light environment. Plant Cell Environ. 37, 1985-1988.

70. Pearcy RW, Krall JP, Sassenrath-Cole GF. 1996 Photosynthesis in Fluctuating Light 
Environments. In Photosynthesis and the Environment (ed NR Baker), pp. 321-346. Dordrecht: Springer Netherlands.

71. Heineke D, Stitt M, Heldt HW. 1989 Effects of inorganic phosphate on the light dependent thylakoid energization of intact spinach chloropalsts. Plant Physiol. , 221-226.

72. Thormählen I et al. 2017 Thioredoxins Play a Crucial Role in Dynamic Acclimation of Photosynthesis in Fluctuating Light. Mol. Plant 10, 168-182.

73. Carrillo LR, Froehlich JE, Cruz JA, Savage LJ, Kramer DM. 2016 Multi-level regulation of the chloroplast ATP synthase: The chloroplast NADPH thioredoxin reductase C (NTRC) is required for redox modulation specifically under low irradiance. Plant J. 87, 654-663.

74. Armbruster U, Correa Galvis V, Kunz H-H, Strand DD. 2017 The regulation of the chloroplast proton motive force plays a key role for photosynthesis in fluctuating light. Curr. Opin. Plant Biol. 37, 56-62.

75. Yin L, Lundin B, Bertrand M, Nurmi M, Solymosi K, Kangasjarvi S, Aro EM, Schoefs B, Spetea C. 2010 Role of thylakoid ATP/ADP carrier in photoinhibition and photoprotection of photosystem II in Arabidopsis. Plant Physiol. 153, 666-677.

76. Flood PJ et al. 2020 Reciprocal cybrids reveal how organellar genomes affect plant phenotypes. Nat Plants 6, 13-21. 